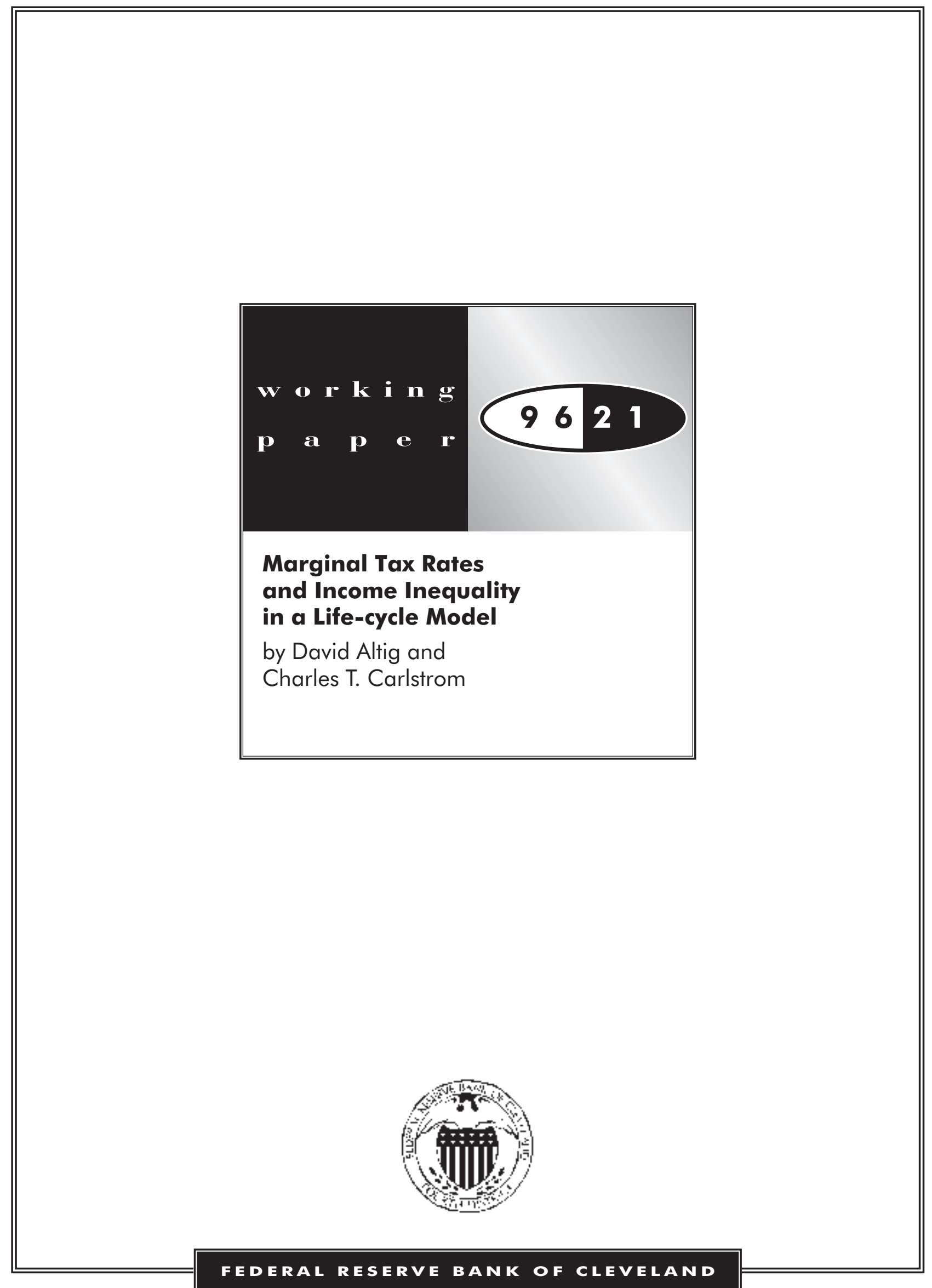


Working Paper 9621

\section{MARGINAL TAX RATES AND INCOME INEQUALITY IN A LIFE-CYCLE MODEL}

by David Altig and Charles T. Carlstrom

David Altig is assistant vice president for economic research at the Federal Reserve Bank of Cleveland, and Charles T. Carlstrom is an economist there. The authors thank seminar participants at Arizona State University, Bowling Green State University, the Federal Reserve System Committee on Macroeconomics, the University of Pennsylvania, and the University of Pittsburgh for many useful comments. They are especially indebted to two anonymous referees for their extensive suggestions for improving this paper.

Working papers of the Federal Reserve Bank of Cleveland are preliminary materials circulated to stimulate discussion and critical comment. The views stated herein are those of the authors and are not necessarily those of the Federal Reserve Bank of Cleveland or of the Board of Governors of the Federal Reserve System.

Federal Reserve Bank of Cleveland working papers are distributed for the purpose of promoting discussion of research in progress. These papers may not have been subject to the formal editorial review accorded official Federal Reserve Bank of Cleveland publications.

Working papers are now available electronically through the Cleveland Fed's home page on the World Wide Web: http://www.clev.frb.org.

December 1996 


\begin{abstract}
In this paper, we perform computational counterfactual experiments to examine the quantitative impact of marginal tax rates on the distribution of income. Our methodology builds on previous simulation models developed by Auerbach and Kotlikoff and Fullerton and Rogers, and uses an algorithm that allows us to examine marginal tax rate structures in their literal form. We find that distortions associated with particular marginal tax rate structures have sizable effects on income inequality in a reasonably quantified life-cycle setting: In our baseline experiments, the change in steady-state income inequality under 1989 U.S. income tax rates vis-à-vis 1984 rates is about half as large as the change actually seen in the data over those two years, when measured in terms of a monetary metric derived from Gini coefficients.
\end{abstract}




\section{Introduction}

This paper is motivated by two well-known observations. The first is that, by almost any measure, income inequality in the United States increased substantially throughout the 1980s. The second is that over the same period of time there were several substantial changes in the U.S. personal income tax code, notably major changes in the structure of marginal tax rates.

With these observations in mind, we ask a straightforward question: What is the plausible magnitude of the effect on the distribution of income from distortions created by changing marginal tax rates. More specifically, in this article we take the marginal tax rate changes indicated by the Tax Reform Act of 1986 (TRA86), and examine the effect on the distribution of income arising from endogenous labor supply and saving responses in a reasonably quantified general equilibrium model with life-cycle consumers.

In our opinion, the question we ask has been incompletely addressed - and, hence, our study is warranted - due to the focus of previous research on other, undeniably important, aspects of the changing income distribution. First, much recent empirical research has concentrated on wage income, and in particular on the growing disparity between returns to high-skill versus low-skill labor. (For an extensive review, see Levy and Murname [1992].) As documented by Karoly (1994), however, wage-income inequality accounts for only part of the recent trend in overall income inequality. Second, studies that explicitly consider changes driven by the tax code have focused on the top of the income distribution (Feenberg and Poterba [1993] and Slemrod [1993], for instance), or on changes in taxable, rather than gross, income (Feldstein [1995], for instance). In both cases, the data is limited in its ability to distinguish the behavioral responses of total labor supply and saving from "income sheltering" activities (for example, a change in the manner in which wealth is accumulated that is not associated with a change the aggregate level of household saving).

We add to the picture drawn by these studies by providing an analysis in the spirit of the computational experiment described by Kydland and Prescott (1996). We begin with an explicit benchmark representation of the U.S. economy, calibrated to match key features of both the macroeconomy and the income distribution under a post-TRA86 marginal tax rate structure (1989, specifically). We then consider a counterfactual economy in which the only exogenous difference from the benchmark is the replacement of the TRA86 rate structure with one taken from a pre-TRA86 year (1984, specifically). Our experiments involve no change in the relative (pre-tax) price of different types of labor, or in the opportunities for sheltering income by altering the form in which income is received. Thus, we examine the quantitative impact on inequality arising solely from behavioral responses associated with labor supply and saving decisions.

Our analysis builds on the computable general equilibrium framework pioneered by Auerbach and Kotlikoff (1987). In particular, we adopt their basic simulation approach, with two key extensions. First, we follow the recent work of Fullerton and 
Rogers (1993) and allow for multiple types of life-cycle agents, each type distinguished by its exogenous labor efficiency profile, and hence by its maximum attainable wealth from human capital. Second, we use a simple algorithm for solving Auerbach-Kotlikoff models with discrete marginal-rate structures. This allows us to introduce tax rate schedules in their literal form.

The bottom line of our study is that the distortions associated with particular marginal tax rate structures have sizable effects on income inequality in a reasonably quantified life-cycle setting. In our baseline experiments, the change in steady state inequality under the 1989 rates vis-a-vis 1984 rates is about half as large as the change found in the data over those two years (when measured in terms of a monetary metric derived from Gini coefficients). The increasing inequality in the model arises in the distribution of both wage- and nonwage-income, despite the fact that, by construction, relative wages are constant across the tax regimes. However, relative to its share of total income, increasing inequality in the distribution nonwage income contributes disproportionately to the change in the Gini across the two steady states. We conclude from these results that endogenous labor supply and saving responses to changes in rate structures like those seen in the 1980s can play a significant role in explaining observed trends in income inequality.

\section{The Model Economy}

\section{A. Basic Demographic Structure}

Our model economy is populated by sequences of distinct cohorts that are distinguished by a) date of birth; b) lifetime labor productivity endowments; and c) their preferences for leaving bequests. Each generation born at a specific date contains 13 different agent types, indexed by $j$, each with different exogenous labor efficiency profiles and distinct utility weights concerning transfers of wealth to their children. All $j$-types of a given generation are identical. With the exception of size, successive generations of $j$-type agents are identical. All agents live for 80 periods with certainty, and each $j$-type generation is $1+n$ times larger than its predecessor.

At "age" 21, each $j$-type cohort gives "birth" to a cohort of the same type. Given our assumption about the exogenous rate of population growth, every newborn cohort is $(1+n)^{20}$ times the size of its "parent" cohort. Also at age 21, each cohort begins its economic life, and begins working, saving, and consuming. We assume that children neither consume nor work prior to separating from the parent households at age 21 . Throughout, then, we will think of an "agent" as being a household, exclusive of children. 


\section{B. Preferences and Household Budget Constraints}

Each $j$-type agent beginning its economic life at calendar date $T$ chooses perfectforesight consumption paths $(c)$, leisure paths $(l)$, and intergenerational transfers $(b)$ to maximize a time-separable utility function of the general form

$$
U_{T}^{j}=\sum_{s=21}^{80} \beta^{s-21} u\left(c_{s, T+s-21}^{j}, l_{s, T+s-21}^{j}, b_{s, T+s-21}^{j}\right),
$$

where $u_{i}>0, u_{i i}<0, \lim _{i \rightarrow \infty}=0, \lim _{i \rightarrow 0}=\infty$, and $u_{i}$ is the partial derivative of the function $u(\cdot)$ with respect to argument $i$. The form of the utility function and the subjective time-discount factor, $\beta$, are assumed to be the same for all agents. We require that $\beta>0$, but need not impose the condition that $\beta<1$.

Letting $a_{s, t}^{j}$ be capital holdings for type $j$ agents, of age $s$, at time $t$, maximization of (1) is subject to a sequence of budget constraints given by

$$
a_{s, t}^{j}=\left(1+r_{t}\right)\left(a_{s-1, t-1}^{j}+g_{s, t}^{j}\right)+w_{s, t}^{j}\left(1-l_{s, t}^{j}\right)+z_{s, t}^{j}-T\left(\bar{y}_{s, t}^{j}\right)-N b_{s, t}^{j} .
$$

The variable $r_{t}$ represents the return to saving, which is held in the form of claims to physical capital. We assume that aggregate wage payments at time $t, w_{t}$, are distributed according to the efficiency levels of individual labor units (i.e. each agent receives the value of its marginal product in exchange for providing labor services). Furthermore, an individual's labor efficiency level is an exogenous function of their age and type, and is denoted by $\varepsilon_{s}^{j}$. Thus, $w_{s, t}^{j}=\varepsilon_{s}^{j} w_{t}$.

For a type- $j$ agent of a given generation, transfers received from parents are represented by the $g_{s, t}^{j}$ in $(2)$, and the $b_{s, t}^{j}$ denote transfers from parents to each of their $N=(1+n)^{20}$ children. (Recall that all $j$-type parents give birth to children of the same type.) Transfers all take the form of exchanges of capital, and are received by children, with interest, at the beginning of the period after they are accumulated by parents. We restrict all parental transfers to bequests, so that $b_{s, t}^{j}=0$, for $s \neq 80$, and $g_{s, t}^{j}=0$, for $s \neq 61$. In the steady state, of course, $g^{j}=b^{j}$, for all $j$ (where we have dropped the age subscripts for convenience).

Finally, $z_{s, t}^{j}$ refers to lump-sum transfers from the government, the function $T\left(\bar{y}_{s, t}^{j}\right)$ determines income-tax payments, and $\bar{y}_{s, t}^{j}$ represents taxable income. We define taxable income as

$$
\bar{y}_{s, t}^{j}=\frac{r_{t}+\pi_{t}}{1+\pi_{t}} a_{s, t}^{j}+w_{s, t}^{j}\left(1-l_{s, t}^{j}\right)-d\left(y_{s, t}^{j}\right)
$$

where $\pi_{t}$ is the rate of inflation between times $t$ and $t-1$, and $d(\cdot)$ specifies deductions and exemptions as a function of gross income. The inflation rate is included in 3 to capture the imperfect nature of indexation in the U.S. tax code. ${ }^{1}$ (Note that this is consistent with the definition of capital income included in adjusted gross income for

\footnotetext{
${ }^{1}$ Indexation in the U.S. personal tax code is effectively done by deflating income in a given year by a lagged value of the gross inflation rate. Imperfections in this scheme arise for two reasons.
} 
tax purposes, and hence is also consistent with the definition implicitly contained in other empirical studies based on actual tax return data.) We do not include explicit taxation of bequests.

Throughout we will assume that $d(\cdot)$ is a linear function of income, with a strictly positive first derivative. Although this assumption is not necessary, it appears to conform to the historical tax structures we consider in that simple linear regressions of deductions plus exemptions on income result in high values (over 0.95) of the resulting $R^{2}$.

We require that the function $T(\cdot)$ be continuous, but not everywhere differentiable. In fact, our subsequent analysis is conducted using U.S. personal income-tax codes that have the familiar discrete step-function marginal rate structures.

\section{Firms and Technology}

Output in the model economy is produced by identical competitive firms using a neoclassical, constant-returns-to-scale production technology. Letting $\gamma^{j}$ be the fraction of $j$-type agents in each generation, aggregate capital $(K)$ and labor $(L)$ (in per capita efficiency units) are obtained from individual asset and labor supplies as

$$
K_{t}=\sum_{j=1}^{13} \gamma^{j} \sum_{s=21}^{80}(1+n)^{80-s-1} a_{s, t-1}^{j},
$$

and

$$
L_{t}=\sum_{j=1}^{13} \gamma^{j} \sum_{s=21}^{80}(1+n)^{80-s} \varepsilon_{s}^{j}\left(1-l_{s, t}^{j}\right) .
$$

Note that, for simplicity, we have normalized the population so that the total number of age- 80 households is one, for all $t$.

Written in terms of the capital-labor ratio, $\kappa$, the aggregate production technology is

$$
q_{t}=f\left(\kappa_{t}\right)
$$

where $q_{t}$ is output per labor input (measured in efficiency units), and $f(\cdot)$ satisfies the usual Inada conditions. The competitive aggregate wage and interest rate are given by

$$
w_{t}=q_{t}-\kappa_{t} f^{\prime}(\cdot)
$$

and

$$
r_{t}=f^{\prime}(\cdot)-\delta
$$

where $\delta$ is the (constant) depreciation rate of physical capital.

First, deflating nominal asset income (approximately $\left.(r+\pi) a_{t-1}\right)$ by a given gross inflation rate, $1+\pi$, overstates real capital income by an amount equal to $\frac{\pi a_{t-1}}{1+\pi}$. The second imperfection arises because the adjustments use lagged, rather than contemporaneous, inflation rates. The first type of imperfection is incorporated into equation (3) The second type, of course, disappears in the steady state, and is not incorporated into (3). Further discussion of this issue can be found in Altig and Carlstrom (1993). 


\section{The Government}

Our interest in this paper is solely in the distortionary effect of different incometax rate structures. Consequently, the government in our model has a very simple role: It raises revenue from income taxes, which it then rebates to the agents from whom the taxes are collected in the form of lump-sum transfers. The government's activities in each period are fully captured by the "rule"

$$
T\left(\bar{y}_{s, t}^{j}\right)=z_{s, t}^{j},
$$

for all $t, s$, and $j$. Thus, our simulations correspond to compensated demand experiments, and the effects of government policy arise only from the distortionary impact of marginal tax rates on household labor supply and saving decisions.

\section{Model Calibration}

Our model is calibrated to Internal Revenue Service Statistics of Income data for the taxable returns of married persons filing jointly in 1989. In what follows, all references to income, taxpayers, and so on, should be understood as applying to this population.

Most of our choices for parameterizing the model are standard. Exceptions involve the special features of our framework, specifically the tax codes, multiple agent structure, and bequest motives. We therefore first turn to a discussion of how we quantify these elements of the model, followed by a discussion of the more familiar choices for (or strategies for choosing) preference and technology parameters.

\section{A. Labor Efficiency Profiles}

The labor efficiency profiles in equations (2) and (5) are of the form

$$
\varepsilon_{s}^{j}=e^{a_{0}^{j}+a_{1}^{j} s+a_{2}^{j} s^{2}+a_{3}^{j} s^{3}} .
$$

Values of the $a$ coefficients for $j$-type groups 1 through 12 - numbered in ascending order of lifetime income - are taken from estimates provided by Fullerton and Rogers (1993, table 4-11). ${ }^{2}$

\footnotetext{
${ }^{2}$ Fullerton and Rogers use data from the Michigan Panel Study of Income Dynamics (PSID) to calculate life-cycle labor efficiency endowments for the twelve groups. Focusing on a subsample that includes only households with stable marital histories over the 1970-1987 period, they first fit a common wage function across all households. Specifically, they regress the log of average hourly earnings for each individual on a cubic in age and the interaction of age and age-squared with sex, education, and race. The coefficients so estimated are used to construct synthetic individual wage observations outside the 18-year sample, which are then combined with actual wage observations to calculate lifetime labor income for all households. Finally, individuals are ranked by lifetime income level and separated into twelve groups according to that ranking, for which distinct wage profiles are then estimated.
} 
In calibrating the model we aim to match two important elements of the income distribution: mean income and the percent of income earned by taxpayers with high income. Unfortunately, we are unable, using the Fullerton-Rogers estimates alone, to simultaneously match average income and generate incomes for the "rich" that are sufficiently high to mimic the actual distribution of income. Our, admittedly ad hoc, solution to this problem is to add a thirteenth $j$-type whose members have an efficiency profile that is proportional to that of the twelfth group. Specifically, the intercept of the profile for this group (i.e. $a_{0}^{13}$ ) is chosen so that the top 6 percent of taxpayers (those with incomes over $\$ 100,000$ in 1989) earn 26 percent of total measured income in the benchmark steady state. ${ }^{3}$

\section{B. Tax Code}

In the benchmark case, we use the actual marginal tax rates applied to personal income in 1989, which reflects the fully phased-in changes introduced by TRA86. Our experiments intentionally exclude many obvious and important forms of tax avoidance - Subchapter C filings and the transformation of compensation into nontaxable benefits, for example. However, we do incorporate personal exemptions and deductions by introducing the function $d(\cdot)$ in the calculation of taxable income (see equation [3]), which posits that such adjustments to income are linear in gross income. To estimate this function, we use the Statistics of Income data to calculate average personal exemptions and deductions by listed income classes, which are then regressed on the midpoint of each income class. ${ }^{4}$ The estimated function is then used to convert gross income to taxable income. (The tax functions are more fully described in figure 5 and equations [13] and [14], below.)

\section{The Production Technology: Scaling the Model}

We adopt a simple Cobb-Douglas production function,

$$
q_{t}=A \kappa_{t}^{\theta},
$$

where $\theta$ is capital's share in production and $A$ is a scale factor. Our benchmark value for $\theta$ is 0.36 , and we assume that physical capital depreciates at a rate of 10 percent per annum. Both of these choices are motivated by familiar long-run observations on capital shares in the U.S. economy. (See, for example, the arguments in Cooley and

\footnotetext{
${ }^{3}$ The population distribution of lifetime income cohorts 1 through 12 is obtained from table 4-11 in Fullerton and Rogers (1993). Letting $\gamma^{j^{\prime}}, j^{\prime}=1 \ldots 12$, be the proportion of weighted observations for the 12 groups in the Fullerton and Rogers data, we choose $\gamma^{13}=0.06$, and then set $\gamma^{j}=\gamma^{j^{\prime}}\left(1-\gamma^{13}\right)$ for $j=1 \ldots 12$. Note, however, that this does not necessarily imply that the top 6 percent of wage earners in a given cross-sectional distribution are all of type 13.

${ }^{4}$ Deductions are calculated as a weighted average of total standard deductions and total itemized deductions in each reported income class, where the weights are determined by the share of income accounted for by taxpayers taking each particular type of deduction.
} 
Prescott [1994].) In addition, we set annual population growth to 1.3 percent, the postwar U.S. average.

Unlike many similar calibrated simulation exercises, the scale factor $A$ does play a role in our experiments. In particular, because our study uses actual marginal rate brackets, it is necessary to scale the model so that generated model incomes can be sensibly applied to the chosen tax codes. Essentially, we choose $A$ so that the mean income generated in the model's benchmark steady state equals the average gross income of joint filers in tax year 1989. In practice (as discussed earlier), matching the data requires that we simultaneously choose the scale factor $A$ and the intercept of the labor efficiency profile for the thirteenth $j$-type group (the "richest" lifetime income type).

\section{Preferences}

We specialize the utility function in (1) to

$$
U_{T}^{j}=\sum_{s=21}^{80} \beta^{s-21}\left(\ln \left(c_{s, T+s-21}^{j}\right)+\alpha \frac{\left(l_{s, T+s-21}^{j}\right)^{1-\sigma}}{1-\sigma}\right)+\beta^{59} \rho^{j} N \frac{\left(b^{j}\right)^{1-\sigma_{b}}}{1-\sigma_{b}} .
$$

In (12), $\alpha$ is the utility weight on leisure, $\sigma$ is the inverse of the elasticity of leisure with respect to wages, and $\sigma_{b}$ is the inverse of the elasticity of bequests with respect to consumption. The parameter $\rho^{j}$ is $j$-type specific utility weight placed on bequests left to children.

This formulation of preferences is chosen for two reasons. First, it is consistent with the existence of balanced growth, in that average hours are invariant to positive rates of labor-augmenting technical progress (see King, Plosser, and Rebelo [1988]). ${ }^{5}$ Second, the specification in equation (12) has the property that, for given marginal tax rates, the capital-labor ratio is invariant to the scale factor $A$ in (11). Both of these features follow from the fact that changes in the level of wages have offsetting income and substitution effects on individual labor supply decisions.

Given the functional form in equation (12), the parameters $\alpha$ and $\sigma$ are, respectively, set to 0.6 and 4 . These choices imply that steady state hours worked by the "average" worker is about 30 percent of their total time endowment (which we take to be 16 hours per day) and an average intertemporal labor supply elasticity of about

\footnotetext{
${ }^{5}$ We have, however, chosen not to to embed exogenous labor-augmenting technical progress into the model. While it is certainly easy, by a suitable change of variables, to solve the model with such an extension, the notion of a steady state becomes somewhat slippery when we contemplate both economic growth and the type of progressive tax systems that we are considering. In particular, in a growing economy with an unchanging tax code, all taxpayers face the highest marginal tax rate in the long run. Although we make an allowance for growth in our benchmark experiment, the steady-state comparisons in our model implicitly assume that the relevant tax codes are indexed to real growth.
} 
$0.5 .^{6}$

Finally, we set $\sigma_{b}$ to 2.0 and, for $j=1, \ldots 12$, choose the $\rho^{j}$ so that each groups endogenous bequest choices match the levels reported in table 3-8 of Fullerton and Rogers (1993). ${ }^{7}$ For cohort 13 we assume that bequests represent the same proportion of peak income as for cohort 12 , and choose $\rho^{13}$ to match this value.

\section{E. Solving the Model}

Before proceeding to a discussion of the benchmark equilibrium and the results of our experiments, we will briefly outline our solution algorithm. A more detailed description is provided in the appendix.

To calibrate the benchmark steady state, we use a modification of the iterative approach suggested by Auerbach and Kotlikoff (1987).

1. Conjecture values for $\rho^{j}$ (the utility bequest weights), $j=1, \ldots 13$.

2. Conjecture values for $A$ (the scale factor in the production function specified in equation [11]) and $a_{0}^{13}$ (the intercept of the labor efficiency profile for type-13 agents).

3. Conjecture values for the aggregate capital stock and labor supply, which in turn imply guesses for the aggregate wage and interest rate from equations (7) and (8).

4. Conjecture marginal tax rates $\tau_{s}^{j}$ for each age $s$ and type $j$.

5. For given values of $r, w$, and the $\tau_{s}^{j}$, calculate life-cycle consumption and leisure paths for each $j$-type. In this stage of the procedure, corner conditions for leisure are resolved.

\footnotetext{
${ }^{6}$ Most empirical studies provide estimates of the intertemporal elasticity of supply in labor $(\eta)$, rather than leisure as in our preference specification in equation (12). Because leisure accounts for approximately two-thirds of the labor endowment, on average $\eta \approx 2 \sigma$. However, because the labor supply elasticity is not constant for this preference specification, we verify that the simulated data is consistent with a value of about 0.5 by constructing an artificial panel of length 20 years for agents with initial ages from 25 to 44, and then estimate the compensated intertemporal elasticity of substitution in labor using the approach outlined in MaCurdy (1981). (We thank an anonymous referee for suggesting this approach.) Doing so yielded the estimate $\hat{\eta}=0.51$, a result very close to the theoretical average. Although at the high end of MaCurdy's estimates for male labor supply, Rogerson and Rupert (1991) and Rogerson, Rupert, and Wright (1996) argue that conventional analyses of male labor supply tend to understate the true degree of intertemporal substitution. Furthermore, our analysis takes the household as the relevant decision making unit, and there is broad agreement that the elasticity is higher for women than for men (see Killingsworth and Heckman [1986]).

${ }^{7}$ For calibration purposes the bequest data in Fullerton and Rogers were converted to 1989 dollars. There is, in general, little evidence to guide us in the choice $\sigma_{b}$. The effect of choosing an alternative value for $\sigma_{b}$ is explored in section VI.
} 
6. Update tax rates by applying calculated income levels to the relevant tax rate schedule. Note that, because of the step-function characteristic of the rate schedule, some agents may be at "kinks" in their budget surfaces. These conditions are resolved in this stage of the solution procedure.

7. Repeat steps (4) and (5) until consumption and leisure choices are consistent with the assumed tax rates used in calculating them.

8. Use equations (4) and (5) to aggregate asset and labor supplies over all ages and $j$-types to find the values $K^{\prime}$ and $L^{\prime}$ implied by the individual decisions for given factor prices. Update guesses for capital and labor and repeat steps (4)-(7) until the updated values $K^{\prime}$ and $L^{\prime}$ are consistent with individual consumption and leisure choices.

9. Update values for variables in step 2 and repeat steps 3 through 8 until average gross income and the share of income earned by the top 6 percent of the income distribution match the appropriate values in the data. (See the discussion in section III.C, above.)

10. Update values for the $\rho^{j}$ and repeat steps 2 through 9 until the endogenously chosen bequests of each $j$-type matches the appropriate values in the data. (See the discussion in section III.D, above.)

The solution procedure is identical for cases other than the benchmark steady state, except that the calibrated values of the $\rho^{j}, A$, and the intercept for the labor efficiency profile for type-13 agents are fixed, eliminating steps $1,2,9$, and 10 . A schematic of the algorithm is shown in figure 1.

\section{F. The Benchmark Equilibrium}

We set the discount parameter $\beta$ in equation (12) to 0.99 so that, given our other parameter choices, the benchmark steady-state pre-tax real interest rate is about 3 percent and the capital-output ratio is about 2.8 (values which are reasonably close to their respective historical averages in the U.S. data ${ }^{8}$ ). In addition to matching these standard aggregate variables, our calibration exercise is designed to deliver congruence of the model's tax- and income-distribution characteristics with those derived from

\footnotetext{
${ }^{8}$ See Siegal (1992), who reports average real interest rates over the 1800-1990 period. We note, for the record, that the rates appear to differ significantly across subperiods. Specifically, real returns to long-term bonds averaged 1.46 percent over the period from 1889-1978, but 5.76 percent outside that interval.

The capital measure from the data refers to the constant-constant net stock of reproducible tangible wealth reported in the January 1992 Survey of Current Business, and includes consumer durables and government capital. With this definition of $K$, the capital-output ratio in the United States averaged about 2.8 for the period from 1959 through 1990.
} 
the 1989 tax-return data. Some of the relevant comparisons along these dimensions are reported in table 1.

As indicated by the Gini coefficients, the distribution of income in the model is somewhat more equal than that exhibited by the data. This results in large part from the fact that, even after the addition of the thirteenth lifetime-income type described in III.A, the framework under represents taxpayer incomes at the highest end of the income distribution. Although our simulations closely match the fraction of income earned by the top 5 percent of income earners - not surprising given that our calibration approach essentially engineers this outcome - the share of the top 1 percent is less than half that found in the data. This difference is clearly seen in the Lorenz curves plotted in figure 2.

A more detailed view of the model's distributional features is shown in figures 3 and 4, which compare actual and simulated distributions of gross income and taxes paid according to the income classes reported in the Statistics of Income. The most significant discrepancy between the model and the data is the concentration of mass in the $\$ 40,000$ to $\$ 50,000$ range, a difference that is especially pronounced for gross income. $^{9}$

As can also be seen in table 1, our benchmark model does quite well at matching the broad characteristics of the actual 1989 tax distribution: Simulated average and average marginal tax rates are virtually identical to the values derived from the data. Furthermore, the simulated distribution of income among the different marginal rate brackets is very close to that obtained from actual tax returns.

\section{The Quantitative Effects of Changes in Marginal Tax Rates}

Our computational experiment begins with the benchmark steady state calibrated to 1989 data, as described in the previous section. We then consider and compare an alternative economy, identical in every way to the benchmark except that the 1989 tax structure used to calibrate the model is replaced with a rate structure taken from the personal income tax code for 1984 . We focus particularly on how the distinct rate structures affect overall income inequality.

The rate structures we consider are depicted in figure 5. The rates are taken from schedule $\mathrm{Y}$ for married persons filing jointly in tax years 1984 and 1989, but for two adjustments. First, the 1984 schedules are adjusted for real income growth between the two years. (Note that, subject to the caveats noted in footnote 1, the tax schedule in 1989 included an adjustment for inflation between the two years.) Under the assumption that income growth (which we are abstracting from) does not itself directly alter the distribution of income, the adjustment amounts to treating the

\footnotetext{
${ }^{9}$ Some discrepancy would be expected due to the fact that our wage efficiency profiles are estimated from data spanning the period from 1970 to 1987, and are not purely consistent with the distribution of wage income in 1989.
} 
rate schedules as being applicable to given regions of the income distribution. (We examine the effect of this adjustment in section V.I.)

Second, the schedules depicted in figure 5 are "effective" rates in the sense that we have incorporated the impact of the functions used to convert gross income into taxable income (see the discussion in section III.B). These functions are

$$
\operatorname{Max}\{\$ 8368 \text { or } \$ 7057+0.1566 \bar{y}\}
$$

for 1984, and

$$
\operatorname{Max}\{\$ 9805 \text { or } \$ 8280+0.1555 \bar{y}\}
$$

for $1989 .{ }^{10}$ (The first term in the brackets represent our implicit "standard deduction.") Note that the two functions are very similar, implying that, for our experiments, most of the difference between the two rate structures is derived from the statutory rate schedule.

\section{A. Aggregate Effects}

A comparison of the long-run equilibria under the 1989 and 1984 rate structures is provided in table 2. Compared to the 1989 benchmark, steady state output is about 6 percent lower under the 1984 tax rate structure. Although the long-run equilibrium levels of both labor and capital inputs fall in the 1984 regime, the decline in the latter is proportionately larger, so that the steady state capital-labor ratio is reduced by introducing the earlier year's rate structure. Thus, the aggregate wage is lower and the interest rate higher in the 1984 case than in the 1989 case.

Revenues collected by the income tax are nearly 16 percent higher under the 1984 tax code. The average income-tax rate under the 1984 structure is about 17 percent (compared to the benchmark value of about 14 percent), and the average marginal tax rate is nearly 32 percent (compared to $23-1 / 2$ percent in the benchmark case). Because the direct wealth effects of the tax differences are offset by lump sum transfers, it is the change in marginal rates that drive the both aggregate and distributional effects in our model.

\section{B. Marginal Tax Rates and the Distribution of Income}

The bottom panel of table 2 summarizes the distributional consequences of our experiment. As measured by the Gini coefficient, the distribution of income becomes more unequal under the 1989 schedule, increasing from 0.33 in the 1984 case to 0.36 in the 1989 case. To provide some intuition for the magnitude of the difference in inequality across the two tax codes, we calculate a measure suggested by Blackburn (1989) that translates differences between Gini values into a monetary metric. Focusing on the steady state distribution of income obtained with the 1984 rates, our

\footnotetext{
${ }^{10}$ The function in equation (13) incorporates the zero-bracket amount provided for in the 1984 code.
} 
application of the Blackburn measure gives the dollar amount that would have to be transferred from all agents with incomes below the median to all those with abovemedian income in order to generate the same degree of inequality realized in the steady state under the 1989 rates. In our experiment this amounts to about $\$ 3000$ (measured in terms of the 1989 price level).

As a frame of reference, it is instructive to compare the results of our counterfactual experiment with actual experience. From 1984 to 1989, the Gini coefficients derived from the Statistics of Income tax data increased from roughly 0.35 to 0.40 (based on an average of the lower and upper bound estimates suggested by Gastwirth [1972]). In terms of the Blackburn measure, the monetary equivalent to this change is a transfer of $\$ 5,776$ from below-median income earners to above-median income earners. Comparing this number to that obtained from the model, our experiment thus indicates a response in the distribution of income from the change in rate structures that is just over 50 percent of the change that actually occurred in the data.

The data further reveal that the share of income earned by the top 5 percent of income earners rose from 19.7 percent in 1984 to 25.7 percent in 1989 . In our model simulations, the corresponding numbers are 19.5 percent and 22.6 percent, roughly 40 percent of the change in the data. The absolute magnitude of the change in the income share of the top 1 percent of the distribution is much smaller in the model than in the data, which is not surprising given that our model significantly underestimates the share earned by "very high" income earners. In the model, the change in the income share of the 1 percent of the distribution is less than 1 percentage point (from 4.6 percent under the 1984 structure to 5.4 percent under the 1989 structure). This compares to a change of just over $4-1 / 2$ percentage points in the data (from 8.9 percent in 1984 to 13.5 percent in 1989).

These comparisons with the data are made solely for the purpose of providing some perspective on the magnitude of the effects predicted by the model. Our conclusion is not that TRA86 explains half the change in the measured Gini coefficient between 1984 and 1989 (or thirty to forty percent of the increase in the mass at the top of the income distribution). For one thing, we have obviously excluded important elements of the Act that may have mitigated or exaggerated its overall impact. ${ }^{11}$ In comparing the model's outcome to the data we are attempting to show that, working solely through the distortionary effect on household saving and labor supply decisions, the impact on inequality from rate structure changes like those implemented by TRA86 are quantitatively meaningful.

\footnotetext{
${ }^{11}$ It is also true that the model is comparing steady states, while the data is separated by only five years. However, our experiments with transition paths indicate that measures of inequality in the model converge very rapidly to levels near their steady state values. These results are reported in an earlier draft of this paper. (Interested readers are referred to Altig and Carlstrom [1995]. The model in that paper has a preference specification that does not include bequests, but is otherwise identical the one used in the experiments reported here.)
} 


\section{A Further Analysis of the Results}

\section{A. Some Cohort-Specific Examples}

To aid in exploring these results a bit further, figure 6 plots the life-cycle profiles of marginal tax rates, labor supply, labor income, asset holdings, and asset income for two specific $j$-types, designated as cohorts 3 and 11 . The income of a representative member of cohort 3 ranges from about $\$ 10,000$ to $\$ 33,000$ in the benchmark steady state. For cohort 11 the range is $\$ 42,000$ to $\$ 98,000$.

The panels in figure 6 clearly reveal a discernible effect of marginal tax rates on the leisure and saving decisions of households. For both types the life-cycle pattern of labor supply decisions clearly reveal the distortionary impact of the tax rate schedules, each exhibiting discrete kinks in the profiles corresponding to the discrete steps in tax rates. With both groups marginal tax rates are lower in the 1989 case for most periods of life, and labor supply is higher. Because the capital-labor ratio is higher under the 1989 structure, the aggregate wage rate, and consequently labor income, are also generally higher.

Changes in labor supply are quite different for the two groups: The cumulative increase in hours provided by group 11 under the 1989 tax regime relative to 1984 is better than 77 percent in excess of group 3's. The greater labor efficiency of cohort 11 then magnifies the responses of total wage income in figure 6 . Thus, inequality in the wage component of income increases across these two types of agents even though the relative wage received remains the same.

With respect to saving behavior, for cohort 3 asset positions and asset income are, on average, lower under the 1989 tax code than under the 1984 code. The converse is true for cohort 11. Thus, as we compare the steady state with 1989 rates to that under 1984 rates, inequality in the nonwage component of income increases across these two types of agents because the asset income of cohort 11 increases and that of cohort 3 decreases.

This particular result - lower nonwage income for cohort 3 under the 1989 rate structure compared to higher nonwage income for cohort 11 - is driven by the combination of tax rate changes and general equilibrium effects on the after-tax real rate of interest. Consider first the case of type- 3 agents. Although the tax rates realized by this cohort are generally higher under the 1984 structure, the tax rate differences relative to the 1989 code are, over most of the cohort's life-cycle, swamped by the higher 1984 pre-tax interest rate (see figure 7). As a result of the higher after-tax interest rates, asset levels and asset income for cohort 3 are thus higher in the general equilibrium calculated with the 1984 rate structure.

To help reinforce this point, figure 7 illustrates the effect of a partial equilibrium experiment in which factor prices are fixed at their steady state values under the 1989 code, and marginal tax rates are fixed at their equilibrium values under the 1984 code. (Recall that, because the steady state capital-labor ratio is lower for 1984 case, the pre-tax real interest rate is higher.) With the interest rate fixed at the lower 1989 
value, after-tax rates for cohort 3 calculated with the 1984 marginal tax rates result in lower post-tax interest rates than in either of the two general equilibrium cases, and so also results in a lower life cycle profile of asset holdings and a lower asset-income profile.

For the type-11 group, the marginal tax rates are sufficiently lower under the 1989 code so as to swamp the general equilibrium pre-tax interest rate differences across the two steady states. As a consequence, and in contrast to the case of cohort 3 , after-tax rates over the life-cycle are higher on average in the benchmark case, which results in higher asset levels and greater asset-income than chosen under the 1984 rate structure.

\section{B. A Decomposition of the Income Gini into Wage and Non- wage Components}

The comparison of the two groups in the previous subsection suggests that, in our experiment, changes in inequality arise from both labor- and capital-income sources. This observation generalizes to the entire distribution. As reported in table 3, separate Gini coefficients for wage and nonwage income components reveal that inequality in both labor and asset sources of income is higher under the 1989 rate structure: The Gini for wage income under the 1989 rate structure is 0.44 , compared to 0.36 in the case of the 1984 structure. For nonwage income, the Ginis are 0.56 versus 0.51 in the 1989 and 1984 cases, respectively.

Using a decomposition suggested by Lerman and Yitzhaki (1985), we find that the rise of inequality in both income sources contribute equally to the change in the overall Gini. ${ }^{12}$ However, the share of the total-income Gini accounted for by nonwage income is only about 25 to 27 percent. Thus, the fact that the change in the nonwageincome distribution accounts for 50 percent of the change in the overall Gini implies that inequality from the asset-income source contributes disproportionately to the rise in overall income inequality. This conforms to the decrease in the share of inequality accounted for by wage income found in the U.S. data over the period from 1980-1990 (see Karoly [1994]).

\footnotetext{
${ }^{12}$ The Lerman-Yitzhaki decomposition yields an expression for the inequality share of income component $k$ given by $I_{k}=\frac{S_{k} G_{k} R_{k}}{G}$, where $S_{k}$ is the component's share of total income, $G_{k}$ is the Gini coefficient for the component, $R_{k}$ is the covariance of the component with the distribution of total income normalized by the covariance of the component with its own distribution (termed the "Gini correlation"), and $G$ is the Gini for total income. By construction, the component shares of inequality must sum to one. Under the 1984 rate structure, $I_{w}=0.754$ and $I_{n w}=0.246$ (where the subscripts refer to $w$ and $n w$ refer to wage and nonwage income respectively). Under the 1989 rate structure the corresponding values are $I_{w}=0.733$ and $I_{n w}=0.267$.
} 


\section{Inequality in the "After-Tax" Income Distribution}

Although lump-sum transfers imply that net tax payments are always zero in our experiments, it is instructive to examine the distributional impact of the two rate structures on income net of income-tax payments. We report these calculations in table $3 .^{13}$ As expected given the progressive nature of both rate structures, each of the after-tax Ginis indicate that net-of-income-tax inequality is less than that of gross income. (Furthermore, as would be anticipated by perusal of figure 5, the difference between the pre- and post-tax distributions is greater under the 1984 code.) Interestingly, the greater inequality associated with 1989 rate structure is amplified by the comparison of the net-of-income-tax distributions: Relative to the results reported in table 2, the Blackburn metric is about $\$ 4216$ for the "after-tax" calculations, or approximately 40 percent higher than for our earlier calculations. Still, the overall picture remains consistent with the conclusion in Karoly (1994) that "pre-tax income inequality dominates any increase in post-tax inequality."

\section{Inequality in and Life-Cycle Income Distribution}

The conclusion that inequality is greater when households face the 1989 rate structure does not depend on the fact that the Gini coefficients are calculated on the basis of cross-sectional, rather than life-cycle, income: The Gini coefficients calculated from the distribution of wealth (the present value of labor income plus bequests) across $j$-types also reveal more inequality under the 1989 code. The rise in the Gini as we move from the 1984 to the 1989 steady state - from 0.26 in the former to 0.29 in the latter - is in fact greater in percentage terms than the change obtained from the cross-sectional calculations. ${ }^{14}$

Ultimately, however, a more meaningful measure of the distributional impact across lifetime income groups would relate the tax structure effects to measures of economic welfare. We turn next, then, to the calculation of utility losses and gains associated with our computational experiment. For any individual living in a long-run equilibrium under the 1984 rate structure, we calculate the welfare gain of shifting to the 1989 structure as the percentage decrease in full wealth that must be taken from an individual in the 1989 steady state in order to maintain utility at its initial level. (Full wealth is defined as the present value of labor income when the individual's entire labor endowment is allocated to market work, plus the present value of bequests.) Positive numbers thus indicate that lifetime utility is higher under the 1989 rates.

\footnotetext{
${ }^{13}$ We thank an anonymous referee for suggesting these calculations.

${ }^{14}$ As found in the cross-sectional income distribution, the increase in the wealth Gini can be attributed to both wage and nonwage sources. However, the contribution of nonwage wealth (defined as the present value of asset income plus bequests) is more pronounced in the lifetime wealth distribution across $j$-types. Using the Lerman-Yitzhaki decomposition described above, we find that about 60 percent of the increase in the wealth-Gini across $j$-types is attributable to the nonwage source.
} 
The welfare results for each of the $13 j$-types are depicted in figure 8 . The average (population-weighted) steady-state welfare gain associated with changing from the 1984 to the 1989 rate structure averages 0.9 percent of full wealth. ${ }^{15}$ In other words, the average household gains by a shift to the marginal tax rates implied by TRA 86 . However, as is clear from figure 8, this average masks a wide range of outcomes for the specific $j$-types. The very wealthiest group (type 13) enjoys a welfare gain equivalent to over 2 percent of its wealth. Cohort 2, on the other hand, suffers a loss of about $1 / 3$ of a percentage point.

These welfare results are largely driven by changes in the rate structures per se, as opposed to general equilibrium effects on factor prices. Figure 8 also shows the welfare results from the partial equilibrium experiments described in subsection A, above. In general, both the quantitative and qualitative outcomes are similar to those obtained from the full general-equilibrium experiments.

At the low end of the lifetime-income scale, there is a reversal in the partial equilibrium experiments of the welfare losses found in the full general equilibrium simulations. As a point of reference, refer back to the labor and asset profiles for type- 3 agents shown in figures 6 and 7 , and recall the dominant effect of the higher interest rate on the saving behavior of this group in the steady state under the 1984 tax rates. ${ }^{16}$ In welfare terms, removing the impact of the higher pre-tax interest rate in the full 1984 general equilibrium simulation is sufficient to shift a zero change in lifetime utility across the tax regimes to a small gain from shifting to the 1989 structure.

These observations notwithstanding, the general implication that the welfare consequences are concentrated at the higher end of the wealth distribution remains. Furthermore the average utility gain from shifting to the 1989 structure barely changes, rising from 0.9 percent of full wealth in the general equilibrium case to 0.95 percent in the partial equilibrium experiment.

\section{Some Alternative Experiments}

To provide a sense of the robustness of our results, we report a summary of several alternative experiments in table 4 . These experiments are

1. The partial equilibrium experiment described in the previous section.

2. Setting $\sigma$ to 10 , implying a labor supply elasticity of about 0.2 .

3. Setting $\rho^{j}=0$, for all $j$, thus eliminating bequests from the model.

4. Setting $\sigma_{b}=4$, implying a bequest elasticity of 0.25 .

\footnotetext{
${ }^{15}$ The essential message of our welfare calculations is not modified by including the transition path analysis. See, again, Altig and Carlstrom (1995).

${ }^{16}$ The pattern of effects shown in figures 6 and 7 , and hence the same general set of observations, apply also to type- 1 and type- 2 lifetime income groups.
} 
5. Eliminating the adjustment of the 1984 rates for real growth between the two tax years, so that the experiment involves a straight comparison of the two rate structures as they appeared in their given tax years.

6. Adjusting the intercept of the adjustment function $d(\cdot)$ in equation (13) so that the two rate structures generate the same aggregate revenue from the income tax.

7. Allowing a deduction equal to 60 percent of nonwage income when calculating taxable income under the 1984 rate structure. ${ }^{17}$

8. Calculating wage income taxes inclusive of the social security tax. The combined OASDI rates applicable to employees and employers together were 10.9 percent in 1984 and 11.8 percent in 1989. As provided for in law, we applied these rates to wage income levels up to $\$ 37,800$ for the 1984 case, and up to $\$ 48,000$ in the 1989 case.

In each of these experiments the model was calibrated as discussed in section III. As is clear from inspection of table 4, none of our major conclusions are altered by the types of revisions contemplated in these experiments. In each case the increase in inequality arising from the 1989 rate structure vis-a-vis the 1984 structure is substantial when measured against the actual change in the distribution of income across those two years. In addition, there are, on average, welfare gains associated with a shift to the 1989 structure, with those gains being concentrated at the upper end of the lifetime income distribution. In general, the rising tide associated with our "tax reform" does not lift all boats: Typically, there are welfare losses at the lower end of the lifetime income distribution, although the effects are small.

We emphasize two aspects of these experiments, in particular. First, our results are quite insensitive to the implied labor supply elasticity. Thus, although the preference parameters chosen for our benchmark experiment maps into elasticities at the high end of many estimates, these choices do not drive our results. This is not particularly surprising given that 50 percent of the model's change in income inequality is due to changes in the distribution of nonwage income. Second, the partial equilibrium experiments - which hold fixed factor prices - suggest the general robustness of our results along transition paths between the two steady states (see footnote 11).

\footnotetext{
${ }^{17}$ The 1984 code allowed for taxation of $40 \%$ of the excess of long-term capital gains over shortterm capital gains. The percentage of nonwage income subject to tax was, of course, greater than the percentage implied by our back-of-the-envelope adjustment. Furthermore, in practice the percentage varied inversely with the income level because higher income taxpayers realized a greater percentage of their nonwage income in capital gains. Our adjustment in this experiment therefore overstates the degree of progressivity inherent in the 1984 capital gains provisions.
} 


\section{Concluding Remarks}

Several studies of recent vintage have examined the distortionary impact of tax rates on individual behavior using a variety of data-based approaches. Although it is generally difficult for these studies to disentangle the channels through which tax effects alter the income distribution, Slemrod [1995] concludes that "... much of the high-income behavioral response to TRA86 is probably better characterized as income shifting, rather than income creation in the sense of increased labor supply." We have adopted a strategy employing a computational methodology in order to isolate reasonable quantitative guesses about the magnitude of "income creation" effects.

In their recent analysis of tax policy and income inequality, Gramlich, Kasten, and Sammartino (1993) conclude: "Not only did actual tax and transfer changes not compensate fully [for the dramatic shift in pre-tax, pre-transfer income over the 1980s], they were not even in the proper direction." Our experiments lead us to a similar conclusion, but for a much different reason. Our analysis indicates that behavioral impact of changes in the marginal tax rate structures like those introduced in TRA86 are likely to have, in and of themselves, contributed substantially to observed changes in the pre-tax distribution of income. We emphasize that, by construction, our computational experiments allow only behavioral responses associated with endogenous labor supply and saving choices or, in Slemrod's words, income creation activities.

We also find that the tax-induced increases in income inequality in our model correspond to rising "welfare inequality." The highest lifetime income groups in our experiments gain both income share and utility from the 1989 structure. The lowest lifetime income groups, on the other hand, suffer utility losses in most variants of our counterfactual simulations, and would prefer living in a steady state with the 1984 rate structure. This occurs despite the fact that aggregate income is higher under the 1989 structure. Thus, in our experiments, the general equilibrium spillover effects do not improve the welfare of those at the bottom of the distribution. In fact, we show that the general equilibrium effects on factor prices actually serve to reduce the lifetime utility of these groups.

Generally, our results illustrate the substantial effects that real-world marginal tax rate differentials can be expected to have in reasonably calibrated general equilibrium models. They thus point to the distortionary effects of marginal tax rates per se as a potentially important element of trends in income inequality in the United States and elsewhere. 


\section{Research Bibliography}

${ }^{1}$ Altig, David and Charles T. Carlstrom, "Marginal Tax Rates and Income Inequality: A Quantitative-Theoretic Analysis," Working Paper 9508, Federal Reserve Bank of Cleveland, August 1995.

${ }^{2}$ Altig, David and Charles T. Carlstrom, "Using Bracket Creep to Raise Revenue: A Bad Idea Whose Time Has Passed," Economic Review, 29, Federal Reserve Bank of Cleveland, Quarter 2, 1993, 2-11.

${ }^{3}$ Cooley, Thomas F. and Edward C. Prescott, "Economic Growth and Business Cycles," in Frontiers of Business Cycle Research, Thomas F. Cooley, ed., Princeton University Press: Princeton, N.J., 1995.

${ }^{4}$ Feenberg, Daniel R. and James M. Poterba, "Income Inequality and the Incomes of the Very High-Income Taxpayers: Evidence From Tax Returns," in Tax Policy and the Economy, James M. Poterba, ed., 1993.

${ }^{5}$ Feldstein, Martin, "The Effect of Marginal Tax Rates on Taxable Income: A Panel Study of the 1986 Tax Reform Act, Journal of Political Economy, 103, June 1995, 551-72.

${ }^{6}$ Fullerton, Don and Diane Lim Rogers, Who Bears the Lifetime Tax Burden? The Brookings Institution: Washington, D.C., 1993.

${ }^{7}$ Gastwirth, Joseph L., "The Estimation of the Lorenz Curve and Gini Index," Review of Economics and Statistics, 54, 1972, 320-22.

${ }^{8}$ Gramlich, Edward M., Richard Kasten, and Frank Sammartino, "Growing Inequality in the 1980s: The Role of Federal taxes and Cash Transfers," in Uneven Tides: Rising Inequality in America, S. Danziger and P. Gottschalk, eds., Russel Sage Foundation: New York, 1993.

${ }^{9}$ Karoly, Lynn A., "Trends in Income Inequality: The Impact of, and Implications for, Tax Policy," in Tax Progressivity, Joel Slemrod, ed., Cambridge University Press: New York, 1994, 95-129.

${ }^{10}$ Killingsworth and James Heckman, "Female Labor Supply: A Survey," in Handbook of Labor Economics, vol. 1, O. Ashenfelter and R. Layard, eds., North-Holland: New York, 1986.

${ }^{11}$ King, Robert G., Charles I. Plosser, and Sergio T. Rebelo, "Production, Growth, and Business Cycles," Journal of Monetary Economics, 21, March/May 1988, $195-232$.

${ }^{12}$ Kydland, Finn E. and Edward C. Prescott, "The Computational Experiment: An Econometric Tool," The Journal of Economic Perspectives, 10, Winter 1996, 6986. 
${ }^{13}$ Lerman, Robert I., and Shlomo Yitzhaki, "Income Inequality Effects by Income Source: A New Approach and Applications to the United States," The Review of Economics and Statistics, 67, 1985, 151-6.

${ }^{14}$ Levy, Frank and Richard J. Murname, "U.S. Earnings Levels and Earnings Inequality: A Review of Recent Trends and Proposed Explanations," Journal of Economic Literature, 30, September 1992, 1333-81.

${ }^{15}$ Macurdy, Thomas, "An Empirical Model of Labor Supply in a Life-Cycle Setting," Journal of Political Economy, 89, 1981, 1059-85.

${ }^{16}$ Rogerson, Richard and Peter Rupert, "New Estimates of Intertemporal Substitution: The Effect of Corner Solutions for Year-Round Workers," Journal of Monetary Economics, 27, April 1991, 255-69.

${ }^{17}$ Rogerson, Richard, Peter Rupert, and Randall Wright, "Homework in Labor Economics: Household Production and Intertemporal Substitution," Working paper, Federal Reserve Bank of Cleveland, 1996.

${ }^{18}$ Siegal, Jeremy J., "The Real Rate of Interest from 1800-1990: A Study of the U.S. and the U.K.," Journal of Monetary Economics, 29, April 1992, 227-52.

${ }^{19}$ Slemrod, Joel, "Income Creation or Income Shifting? Behavioral Responses to the Tax Reform Act of 1986," American Economic Review, 85, May 1995, 175-80.

${ }^{20}$ Slemrod, Joel, "On the High-Income Laffer Curve," Working Paper No. 93-5, Office of Tax Policy Research, University of Michigan, March 1993. 
Table 1: Tax and Distributional Characteristics of Benchmark Model

\begin{tabular}{|l|c|c|}
\cline { 2 - 3 } \multicolumn{1}{c|}{} & Model & Data $^{a}$ \\
\hline Gini Coefficient & 0.359 & $\begin{array}{c}\text { Lower Bound }^{b}: 0.394 \\
\text { Upper Bound }^{b}: 0.404\end{array}$ \\
\hline Fraction of Income Earned by: & & \\
Top 5\% of Income Earners & 0.226 & 0.257 \\
Top 1\% of Income Earners & 0.056 & 0.135 \\
\hline Average Tax Rate & 0.139 & 0.136 \\
\hline Average Marginal Tax Rate & \\
\hline Share of Gross Income for & 0.235 & 0.240 \\
Taxpayers with Marginal Rate & \\
.15 & & \\
.28 (Lower) & 0.388 & 0.345 \\
.33 & 0.352 & 0.387 \\
.28 (Upper) & 0.113 & 0.128 \\
\hline
\end{tabular}

a. All data pertain to taxable returns of married persons filing jointly in 1989, and are taken from Statistics of Income: Individual Tax Returns 1989 and SOI Bulletin, Spring 1993

$b$. Upper and lower bounds are calculated using the formulas suggested in Gastwirth (1972).

c. Average marginal rates are weighted averages, with the weights determined by the taxpayers' shares of gross income.

$d$. Pertains to the population of taxpayers with taxable income.

Sources: Internal Revenue Service; and authors' calculations. 


\section{Table 2: Steady State Comparisons of Alternative Marginal Tax Rate Structures}

\begin{tabular}{|c|c|c|}
\hline Aggregate Comparisons & $\mathbf{1 9 8 4}$ & $\begin{array}{c}\mathbf{1 9 8 9} \\
\text { (Benchmark) }\end{array}$ \\
\hline Output (Relative to Benchmark) & 0.94 & - \\
\hline $\begin{array}{c}\text { Total Income Tax Revenue } \\
\text { (Relative to Benchmark) }\end{array}$ & 1.16 & - \\
\hline Average Tax Rate & 0.17 & 0.14 \\
\hline Average Marginal Tax Rate & 0.32 & 0.24 \\
\hline Distributional Comparisons & & \\
\hline Gini Coefficient (Income) & 0.331 & 0.359 \\
\hline Blackburn Inequality Measure & \\
\hline Fraction of Income Earned by: & $\$ 2993$ & - \\
Top 5\% of Income Earners & 0.195 & 0.226 \\
Top 1\% of Income Earners & 0.046 & 0.054 \\
\hline
\end{tabular}

a. Dollar amount of lump-sum transfers that must be made from all individuals with income below the median to all individuals with income above the median in order to maintain the Gini inequality index at its benchmark value. See Blackburn (1989). 
Table 3: Inequality by Income Source

\begin{tabular}{|l|c|c|}
\cline { 2 - 3 } \multicolumn{1}{c|}{} & $\mathbf{1 9 8 4}$ & $\begin{array}{c}\mathbf{1 9 8 9} \\
\text { (Benchmark) }\end{array}$ \\
\hline Gini Coefficient for Wage Income $^{c}$ & 0.359 & 0.441 \\
\hline Wage Income Share of Inequality $^{a}$ & 0.754 & 0.733 \\
(Percent Contribution to Total Change) $^{b}$ & $(49.2)$ & - \\
\hline Gini Coefficient for Nonwage Income $^{c}$ & 0.513 & 0.563 \\
\hline Nonwage Income Share of Inequality $^{a}$ & 0.246 & 0.267 \\
(Percent Contribution to Total Change) $^{b}$ & $(50.8)$ & - \\
\hline Gini Coefficient for "After-tax" Income $^{c}$ & 0.285 & 0.327 \\
(Ratio to Gross Income Gini) $^{d}$ & $(0.863)$ & $(0.910)$ \\
\hline Blackburn Inequality Measure & & \\
for After-Tax Gini & $\$ 4216$ & - \\
(Ratio to Gross Income Measure) $^{d}$ & $(1.409)$ & - \\
\hline
\end{tabular}

a. Share of inequality calculated using the Lerman-Yitzhaki (1985) decomposition of the total-income Gini coefficient.

$b$. Percent of absolute change in total-income Gini accounted for by income source calculated using the Lerman-Yitzhaki (1985) decomposition.

c. Defined as income less income-tax payments. The "after-tax" income measure does not include lump-sum transfers.

d. See notes to table 2 . 
Table 4: Alternative Experiments ${ }^{a}$

\begin{tabular}{|c|c|c|c|}
\hline & 1984 & $\begin{array}{c}1989 \\
\text { (Benchmark) }\end{array}$ & $\begin{array}{l}\text { Blackburn } \\
\text { Measure }^{b}\end{array}$ \\
\hline Benchmark Model & 0.331 & 0.359 & $\$ 2993$ \\
\hline Partial Equilibrium & 0.333 & 0.359 & $\$ 2768$ \\
\hline Lower Leisure Elasticity: $\sigma=10$ & 0.331 & 0.359 & $\$ 2895$ \\
\hline Higher Bequest Elasticity: $\sigma_{b}=4$ & 0.330 & 0.358 & $\$ 2975$ \\
\hline No Bequests & 0.331 & 0.361 & $\$ 3168$ \\
\hline Rates Unadjusted for Growth & 0.329 & 0.358 & $\$ 2996$ \\
\hline Equal Revenue & 0.328 & 0.359 & $\$ 3294$ \\
\hline $40 \%$ Capital-Income Exemption & 0.335 & 0.359 & $\$ 2500$ \\
\hline Social Security Taxes Included & 0.333 & 0.360 & $\$ 2873$ \\
\hline
\end{tabular}

\begin{tabular}{|l|cccc|}
\cline { 2 - 5 } \multicolumn{1}{c|}{} & \multicolumn{4}{c|}{ Welfare Gains $^{c}$} \\
\multicolumn{1}{c|}{ Average } & Types 1-3 & Types 4-10 & Types 11-13 \\
\hline Benchmark Model & 0.90 & -0.13 & 0.30 & 1.47 \\
\hline Partial Equilibrium & 0.95 & 0.20 & 0.40 & 1.45 \\
\hline $\begin{array}{l}\text { Lower Leisure } \\
\text { Elasticity: } \sigma=10\end{array}$ & 0.49 & -0.12 & 0.15 & 0.83 \\
\hline $\begin{array}{l}\text { Higher Bequest } \\
\text { Elasticity: } \sigma_{b}=4\end{array}$ & 0.93 & -0.11 & 0.31 & 1.51 \\
\hline No Bequests & 0.81 & -0.35 & 0.19 & 1.38 \\
\hline $\begin{array}{l}\text { Rate Unadjusted } \\
\text { for Growth }\end{array}$ & 1.08 & -0.14 & 0.46 & 1.71 \\
\hline Equal Revenue & 0.78 & -0.16 & 0.14 & 1.36 \\
\hline $\begin{array}{l}\text { 40\% Capital-Income } \\
\text { Exemption }\end{array}$ & 0.78 & -0.19 & 0.14 & 1.38 \\
\hline $\begin{array}{l}\text { Social Security } \\
\text { Taxes Included }\end{array}$ & 0.86 & -0.09 & 0.24 & 1.40 \\
\hline
\end{tabular}

$a$. See text for explanations of the experiments.

b. See notes to table 2 .

c. Entries represent percent of full wealth that must be transferred from individual in steady state under 1989 marginal tax rate structure in order to maintain utility level realized in the steady state under 1984 marginal tax rate structure. 


\section{Technical Appendix to "Marginal Tax Rates and Income Inequality in a Life-Cycle Model"}

\section{Basic Demographic Structure of Model}

- At each time there are 80 overlapping generations.

- Generations correspond to children aged 1-20 and adults aged 21-80.

- Only adults make economic decisions. The presence of children has no effect on the preferences of parents.

- At age 21 , each generation has $N=(1+n)^{20}$ children, where $n$ is the exogenous rate of population growth.

- All generations die with certainty at age 80 .

- Each generation consists of 13 different types that are distinguished by the lifetime wealth cohort to which they belong. The types are numbered in ascending order from 1 to 13 according to lifetime wealth. The fraction of the total population accounted for by each of the $j=1, \ldots, 13$ types is denoted by $\gamma^{j}$.

- The exogenous wage efficiency profiles for types 1-12 are taken from the estimates of Fullerton and Rogers. The profile for type 13 is chosen as part of our calibration procedures.

- All agent-types have distinct preferences over bequests left to children.

\section{The Individual Choice Problem}

\section{Preferences}

- Suppressing time subscripts for notational simplicity, types $j=1$..13 have preferences given by

$$
U\left(C^{j}, L^{j}\right)=\sum_{s=21}^{80} \beta^{(s-21)}\left[\ln \left(c_{s}^{j}\right)+\alpha \frac{\left(l_{s}^{j}\right)^{1-\sigma}}{1-\sigma}\right]+\beta^{59} \rho^{j} N \frac{\left(b^{j}\right)^{1-\sigma_{b}}}{1-\sigma_{b}} .
$$

where $\alpha$ is a utility weight on leisure, $\sigma$ is the inverse of the intertemporal elasticity of substitution in leisure, and $\sigma_{b}$ is the inverse of the elasticity of bequests with respect to consumption. The parameter $\rho^{j}$ is a $j$-type specific utility weight placed on bequests left to children. 
- Utility is maximized over the path of consumption and leisure chosen subject to the sequence of budget constraints

$$
c_{s}^{j}=\varepsilon_{s}^{j} w\left(1-l_{s}^{j}\right)\left(1-\tau_{s}^{j}\right)+\left[1+r\left(1-\tau_{s}^{j}\right)\right] a_{s-1}^{j}+T_{s}^{j}+g_{s}-a_{s}^{j}-N b_{s},
$$

where $b_{s}=0$ for $s \neq 80$. The variable $g_{s}$ are bequests received from parents. Because the bequests are made following the parents' death, $g_{s}=(1+r) b$ for $s=60$, and are zero otherwise.

- Assuming that all distortionary tax payments are rebated via lump sum transfers, the wealth constraint for all types is

$$
\sum_{s=21}^{80}(1+r)^{-(s-21)} c_{s}^{j}+(1+r)^{-(80-21)} N b=\sum_{s=21}^{80}(1+r)^{-(s-21)} \varepsilon_{s}^{j} w\left(1-l_{s}^{j}\right)+(1+r)^{-(60-21)}(1+r) b .
$$

- Leisure cannot exceed the total time endowment, which here is normalized to one. Thus, we also add the constraint $l_{s}^{j} \leq 1$, for all $s$ and $j$.

\section{First-order conditions}

- Dropping the $j$ superscripts for convenience, the FOCs (assuming interior solutions) are

$c:$

$$
\beta^{(s-21)} c_{s}^{-1}-\lambda_{s}=0
$$

$l:$

$$
\beta^{(s-21)} \alpha l_{s}^{-\sigma}-\lambda_{s} \varepsilon_{s} w_{s}\left(1-\tau_{s}\right)=0,
$$

$a:$

$$
\lambda_{s}-\lambda_{s+1}\left[1+r\left(1-\tau_{s}\right)\right]=0
$$

$b:$

$$
\rho N \beta^{(80-21)} b^{-\sigma_{b}}-\lambda_{80} N=0 .
$$

\section{Solving for Consumption and Leisure Paths}

Given values for the aggregate variables $r$ and $w$, consumption and leisure choices for types 1-13 can be solved as follows:

- We wish to solve for $c_{21}$ as a function of parameters and aggregate variables. Ignoring retirement for the moment, first use equation (2) to solve for $\lambda_{s}$ :

$$
\lambda_{s}=\frac{\beta^{(s-21)} \alpha l_{s}^{-\sigma}}{\varepsilon_{s} w\left(1-\tau_{s}\right)}
$$


Substituting into (1):

$$
\beta^{(s-21)} c_{s}^{-1}=\frac{\beta^{(s-21)} \alpha l_{s}^{-\sigma}}{\varepsilon_{s} w\left(1-\tau_{s}\right)}
$$

Solving for $l_{s}$ :

$$
l_{s}=\phi_{s} c_{s}^{\frac{1}{\sigma}}
$$

where $\phi_{s}=\left[\frac{\varepsilon_{s} w\left(1-\tau_{s}\right)}{\alpha}\right]^{-\frac{1}{\sigma}}$.

From (3),

$$
\begin{aligned}
\beta^{(s-21)} c_{s}^{-1} & =\beta^{(s-20)}\left[1+r\left(1-\tau_{s+1}\right)\right] c_{s+1}^{-1} \\
c_{s+1} & =\beta\left[1+r\left(1-\tau_{s+1}\right)\right] c_{s} .
\end{aligned}
$$

To handle the case of retirement, we first replace each of the $w_{s}$ in the budget constraint with $w_{s}^{*}=\iota_{s} w_{s}$, where $\iota_{s}=1$ if $\left(1-l_{s}\right)>0$, and $\iota_{s}=0$ if $\left(1-l_{s}\right) \leq 0$. Second, equation (5) is omitted and $l_{s}$ is constrained to equal unity. Substituting equation (5) into the wealth constraint (and using the parameter $\iota_{s}$ defined above) gives

$$
\begin{aligned}
& \sum_{s=21}^{80}(1+r)^{-(s-21)} c_{s}+(1+r)^{-(80-21)} N b \\
&= w \sum_{s=21}^{80}(1+r)^{-(s-21)} \iota_{s} \varepsilon_{s}-w \sum_{s=21}^{80}(1+r)^{-(s-21)} \iota_{s} \varepsilon_{s} \phi_{s} c_{s}^{\frac{1}{\sigma}}+(1+r)^{-(60-21)}(1+r) b . \\
& \Longrightarrow \\
& \sum_{s=21}^{80}(1+r)^{-(s-21)} c_{s}+\left[\frac{N-(1+r)^{19}}{(1+r)^{59}}\right] b=w \sum_{s=21}^{80}(1+r)^{-(s-21)} \iota_{s} \varepsilon_{s}-w \sum_{s=21}^{80}(1+r)^{-(s-21)} \iota_{s} \varepsilon_{s} \phi_{s} c_{s}^{\frac{1}{\sigma}} .
\end{aligned}
$$

By recursive substitution of equation (6):

$$
\begin{gathered}
c_{21}\left(1+\sum_{s=22}^{80}(1+r)^{-(s-21)} \prod_{i=22}^{s} \Lambda_{i}\right) \quad+c_{21}^{\frac{1}{\sigma}} w\left(\iota_{21} \varepsilon_{21} \phi_{21}+\sum_{s=22}^{80}(1+r)^{-(s-21)} \iota_{s} \varepsilon_{s} \phi_{s} \prod_{i=22}^{s} \Lambda_{i}^{\frac{1}{\sigma}}\right. \\
+\left[\frac{N-(1+r)^{19}}{(1+r)^{59}}\right] b=w \sum_{s=21}^{80}(1+r)^{-(s-21)} \iota_{s} \varepsilon_{s}
\end{gathered}
$$

where $\Lambda_{i}=\beta\left[1+r\left(1-\tau_{s}\right)\right]$. For $s=80$,

$$
\lambda_{80}=\beta^{59} c_{80}^{-1}
$$

From equation (4) we can then obtain

$$
b=\left[\frac{1}{\rho c_{80}}\right]^{-\frac{1}{\sigma_{b}}} .
$$


The implicit equation for $c_{21}$ thus becomes

$$
\begin{aligned}
& c_{21}\left(1+\sum_{s=22}^{80}(1+r)^{-(s-21)} \prod_{i=22}^{s} \Lambda_{i}\right)+c_{21}^{\frac{1}{\sigma}} w\left(\iota_{21} \varepsilon_{21} \phi_{21}+\sum_{s=22}^{80}(1+r)^{-(s-21)} \iota_{s} \varepsilon_{s} \phi_{s} \prod_{i=22}^{s} \Lambda_{i}^{\frac{1}{\sigma}}\right) \\
& +\left[\frac{N-(1+r)^{19}}{(1+r)^{59}}\right]\left[\frac{1}{\rho c_{80}}\right]^{-\frac{1}{\sigma_{b}}}- \\
& w \sum_{s=21}^{80}(1+r)^{-(s-21)} \iota_{s} \varepsilon_{s}=0
\end{aligned}
$$

Substituting for $c_{80}$ yields

$$
\begin{aligned}
& c_{21}\left(1+\sum_{s=22}^{80}(1+r)^{-(s-21)} \prod_{i=22}^{s} \Lambda_{i}\right)+c_{21}^{\frac{1}{\sigma}} w\left(\iota_{21} \varepsilon_{21} \phi_{21}+\sum_{s=22}^{80}(1+r)^{-(s-21)} \iota_{s} \varepsilon_{s} \phi_{s} \prod_{i=22}^{s} \Lambda_{i}^{\frac{1}{\sigma}}\right) \\
& +c_{21}^{\frac{1}{\sigma_{b}}}\left[\frac{N-(1+r)^{19}}{(1+r)^{59}}\right]\left[\frac{1}{\rho}\right]^{-\frac{1}{\sigma_{b}}} \prod_{i=22}^{80} \Lambda_{i}^{\frac{1}{\sigma_{b}}}- \\
& w \sum_{s=21}^{80}(1+r)^{-(s-21)} \iota_{s} \varepsilon_{s}=0
\end{aligned}
$$

- Given the solution for $c_{21}$, the entire path of consumption and leisure can be derived from equations (5) and (6).

\section{Notes on the Solution Algorithm for Individual Choice Problem}

Note: In what follows, the symbol " $\simeq$ " should be read to mean "is sufficiently close to".

\section{A. Consumption and Leisure Paths for Given Marginal Tax Rates}

For all $j$ :

1. Set $\iota_{s}=1$ for all $s$. For given factor prices $(r$ and $w)$ and marginal tax rates $\left(\tau_{s}\right)$, solve for $c_{21}$. Use equations (5) and (6) to solve for $c_{s}, s=22, \ldots, 80$, and $l_{s}, s=21, \ldots 80$. Solve for $\mathrm{b}$ from equation (8).

2. If $\left(1-l_{s}\right)>0$, then set $\iota_{s}=1$, and $l_{s}$ according to equation (5). If $\left(1-l_{s}\right) \leq 0$, set $\iota_{s}=0$, and $l_{s}=1$.

3. Recalculate consumption path taking the $\iota_{s}$ calculated from step 2 as given. Calculate implied $l_{s}$ from equation (5). 
4. If $l_{s}=1$ from step 2 and $l_{s}<1$ from step 3 , then set value of $l_{s}$ to that calculated in step 3 . Otherwise, keep $l_{s}$ set to 1 .

5. Repeat steps 2, 3, and 4 until step 2 yields no cases in which $\left(1-l_{s}\right)<0$.

6 . Set $a_{21}=0$ and calculate asset paths $\left(a_{s}, s=22, \ldots, 80\right)$ from the budget contraints. (Recall that $g=(1+r) b$.)

7. Verify that $b \geq 0$ and $a_{80}=N b$.

\section{B. Iterations on Tax Rates}

1. Given the consumption and leisure paths described in subsection III.A, define gross income at each age $s$ as $y_{s}=\varepsilon_{s}\left(1-l_{s}\right) w+\frac{(r+\pi) a_{s-1}}{1+\pi}$, and taxable income as $y_{s}-d_{s}$, where $d_{s}$ represents deductions (defined below).

2. For $k$ tax brackets, let $\widetilde{y}_{k}$ be the maximum amount of income applicable to a given bracket.

3. Let $\tau_{s}$ represent the marginal tax rate at age $s$ under which the consumption and leisure paths described in subsection III.A are calculated. Let $\tau_{s}^{\prime}$ represent new values of tax rates consistent with the current iteration of consumption and leisure paths. Define $\delta_{s}$ as a parameter that controls the updating of tax rates for the next iteration of consumption and leisure paths. The parameter $\delta_{s}$ takes on the values 0 or $\delta^{\prime}>0$. Define the logical variable tax_convergence, which indicates whether further iterations on tax rates are necessary. Begin iterations with tax_convergence $=$ TRUE.

4. For each age $s$, determine the appropriate tax rate given $y_{s}$. [Note: To apply tax rates, model-generated income is scaled up by the ratio of mean actual income to mean model income. (See the notes on calibration below.) Income levels are rescaled downward after determination of appropriate tax rates.]

5. If $y_{s} \simeq \widetilde{y}_{1}$ (in which case the individual is at a "kink" in the budget surface), set $\delta_{s}=0$. If not, then check if $\tau_{1} \simeq \tau_{s}$. If true, then set $\delta_{s}=0$ and $\tau_{s}=\tau_{s}^{\prime}$. If not, set $\delta_{s}=\delta^{\prime}$ and tax_convergence $=F A L S E$.

6. For $y_{s}>\widetilde{y}_{1}$ : If $\tau_{s}^{\prime} \simeq \tau_{s}$, then set $\delta_{s}=0$. If not, loop over the tax brackets to find the maximum $k$ for which $y<\widetilde{y}_{k}$. If $y_{s} \simeq \widetilde{y}_{k}$ (in which case the individual is at a "kink" in the budget surface), set $\delta_{s}=0$. If not, set $\delta_{s}=\delta^{\prime}$ and tax_convergence $=$ FALSE.

7. Update tax rates for next iteration on consumption and leisure paths using the formula $\tau_{s}=\tau_{s}+\delta_{s}\left(\tau_{s}^{\prime}-\tau_{s}\right)$.

8. Repeat consumption, leisure, and tax rate iterations until full tax rate procedure ends with tax_convergence $=T R U E$. 


\section{Iterations on Aggregate Capital and Labor}

1. Define the current aggregate capital stock as $K=\sum_{j=1}^{13} \gamma^{j} \sum_{s=21}^{80}(1+n)^{80-s-1} a_{s-1}$, and the current aggregate labor supply as $L=\sum_{j=1}^{13} \gamma^{j} \sum_{s=21}^{80}(1+n)^{80-s} \varepsilon_{s}^{j}\left(1-l_{s}^{j}\right)$.

2. Let $K_{O L D}$ and $L_{O L D}$ be the values under which a given set of consumption, leisure, and tax rate calculations are made. Define $K_{N E W}$ and $L_{N E W}$ to be calculations of capital and labor made following convergence of steps III.A and III.B.

3. If $K_{N E W} \simeq K_{O L D}$ and $L_{N E W} \simeq L_{O L D}$, then the algorithm has converged to the fixed point mapping from individual choices to the aggregate equilibrium. If not, then update capital and labor according to the formulas $K=K_{O L D}+$ $\Lambda\left(K_{N E W}-K_{O L D}\right)$ and $L=L_{O L D}+\Lambda\left(L_{N E W}-L_{O L D}\right)$, and repeat steps III.AIII.C until the conditions $K_{N E W} \simeq K_{O L D}$ and $L_{N E W} \simeq L_{O L D}$ are satisfied.

\section{Calibration Issues}

The model will calibrated to individual tax return data from tax year 1991. The universe of the data is chosen to be taxable returns for married persons filing jointly. Given the basic technology and preference parameters, the tax code, and the exogenous labor productivity profiles for lifetime wealth types 1-12 (from Fullerton and Rogers), five critical sets of parameters remain: the production scale parameter, the intercept of the wage efficiency profiles for type 13. Conceptually, these parameters are simultaneously chosen according to the following criteria:

- Given an aggregate production technology specified as $y=A \kappa^{\theta}$, where $\kappa$ is the aggregate capital-labor ratio, $A$ is chosen so that average income is equal to $\$ 52,511$ (AGI divided by total returns for joint filers with taxable returns).

- The intercept terms of the wage efficiency profiles for type 13 individuals, i.e. $\varepsilon_{21}^{13}$, is chosen so that the top 6 percent of income earners account for 26 percent of total income. (Note: This is equal to the return- and AGI-shares of filers with adjusted gross incomes over $\$ 100,000$.) The slope of the profile for type 13 is chosen to be identical to the type-12 estimates provided by Fullerton and Rogers. Also, we set the share of the population of the type- 13 cohorts to be equal to the return-share of taxpayers with incomes over $\$ 100,000$.

- Finally, the bequest parameters $\rho$ are chosen so that each $j$-type agent leaves the level of bequests implied by table 3-8 of Fullerton and Rogers. (For type-13 agents we assume that bequests represent the same proportion of peak income as for type-12 agents.) 


\section{A. Algorithm for Scaling the Model}

1. Prior to initial calculations of consumption, leisure, and tax rates, set $\varepsilon_{21}^{13}, \rho$, and $A=\frac{52,511}{\text { Mean-Model-Income }}$.

2. Define Mean - Model - Income as $\bar{Y}=\sum_{j=1}^{14} \gamma^{j} \sum_{s=21}^{80}(1+n)^{80-s} y_{s}^{j}$. Let $\bar{Y}_{O L D}$ be the mean income assumed in solving the individual choice problem for any given iteration, and $\bar{Y}_{N E W}$ be the new mean income obtained after solving that problem.

3. If $\bar{Y}_{N E W} \simeq \bar{Y}_{O L D}$, then $A^{*}=\frac{52,511}{\bar{Y}_{O L D}}$. If not, then set mean income for the next iteration through the individual choice problem according to the formula $\bar{Y}=\bar{Y}_{O L D}+\delta_{\bar{Y}}\left(\bar{Y}_{N E W}-\bar{Y}_{O L D}\right)$.

4. Choosing the human capital parameter $\varepsilon_{21}^{13}=\varepsilon^{*}$ is accomplished by finding values such that, given $\rho$ and $A^{*}$, the income of those earning $\$ 100,000$ or more account for approximately 26 percent of total income (see discussion immediately preceding this subsection). Denote the fraction of the model income accounted for by those earning more than $\$ 100,000$ by $\Psi$. After determining $A^{*}$ from steps 2 and 3 , if $\Psi \simeq 0.279$, then set $\varepsilon^{*}=\varepsilon_{21}^{13}$. If not, define an initial adjustment factor $\delta_{\varepsilon}$, and predefined (constant) adjustment limits $\underline{\delta}_{\varepsilon}$ and $\bar{\delta}_{\varepsilon}$ (where $\underline{\delta}_{\varepsilon}<\bar{\delta}_{\varepsilon}$ ). If $\Psi>0.26$, then update $\varepsilon_{21}^{13}$ by $\delta_{\varepsilon}^{\prime}=\frac{\delta_{\varepsilon}+\bar{\delta}_{\varepsilon}}{2}$, and repeat steps 2 and 3. If $\Psi<0.26$, then update $\varepsilon_{21}^{13}$ by $\delta_{\varepsilon}^{\prime}=\frac{\delta_{\varepsilon}+\underline{\delta}_{\varepsilon}}{2}$, and repeat steps 2 and 3 . Continue iterating in this fashion until the condition $\Psi \simeq 0.26$ is satisfied.

\section{B. Algorithm for Solving for the Utility Weights for Bequests}

1. Let $\hat{b}^{j}$ denote the target level of total bequests for type- $j$ agents. Choosing the $\rho^{j^{*}}$ is accomplished by finding the values such that, given values of $A^{*}$ and $\varepsilon^{13^{*}}$, $N b^{j} \simeq \hat{b}^{j}$ for all $j$. After determining $A^{*}$ and $\varepsilon^{*}$ from steps 2-4, if $N b^{j} \simeq \hat{b}^{j}$, then set $\rho^{j^{*}}=\rho$. If not, define an initial adjustment factor $\delta_{\rho}$, and predefined (constant) adjustment limits $\underline{\delta}_{\rho}$ and $\bar{\delta}_{\rho}$ (where $\underline{\delta}_{\rho}<\bar{\delta}_{\rho}$ ). If $N b^{j}>\hat{b}^{j}$, then update $\rho$ by $\delta_{\rho}^{\prime}=\frac{\delta_{\rho}+\bar{\delta}_{\rho}}{2}$, and repeat steps 2-4. If $N b^{j}<\hat{b}^{j}$, then update $\rho$ by $\delta_{\rho}^{\prime}=\frac{\delta_{\rho}+\underline{\delta}_{\rho}}{2}$, and repeat steps $2-4$. Continue iterating in this fashion until the condition $N b^{j} \simeq \hat{b}^{j}$ is satisfied. 
Figure 1: Schematic of Solution Algorithm

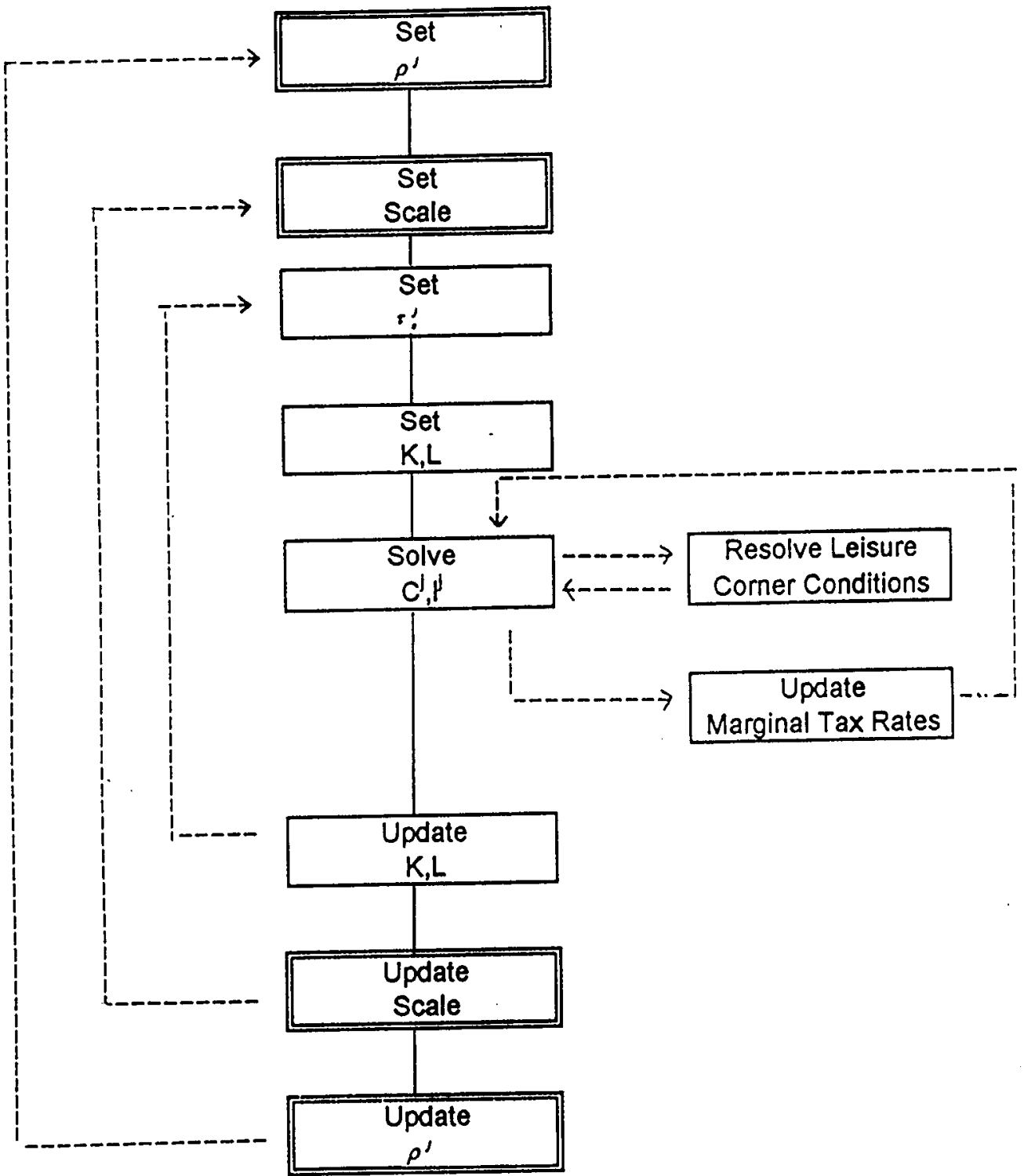

Notes:

Dashed lines represent iterative loops.

Double-line boxes indicate steps relevant only for calibration $\odot$

$\rho^{\prime} \quad$ refers to the type-specific utility weights on bequests $\odot$

Scale refers to the technology parameter, $A$, and the intercept of the efficiency profits

for type-13 agents. 
Figure 2: Lorenz Curves: Data vs. Benchmark Model

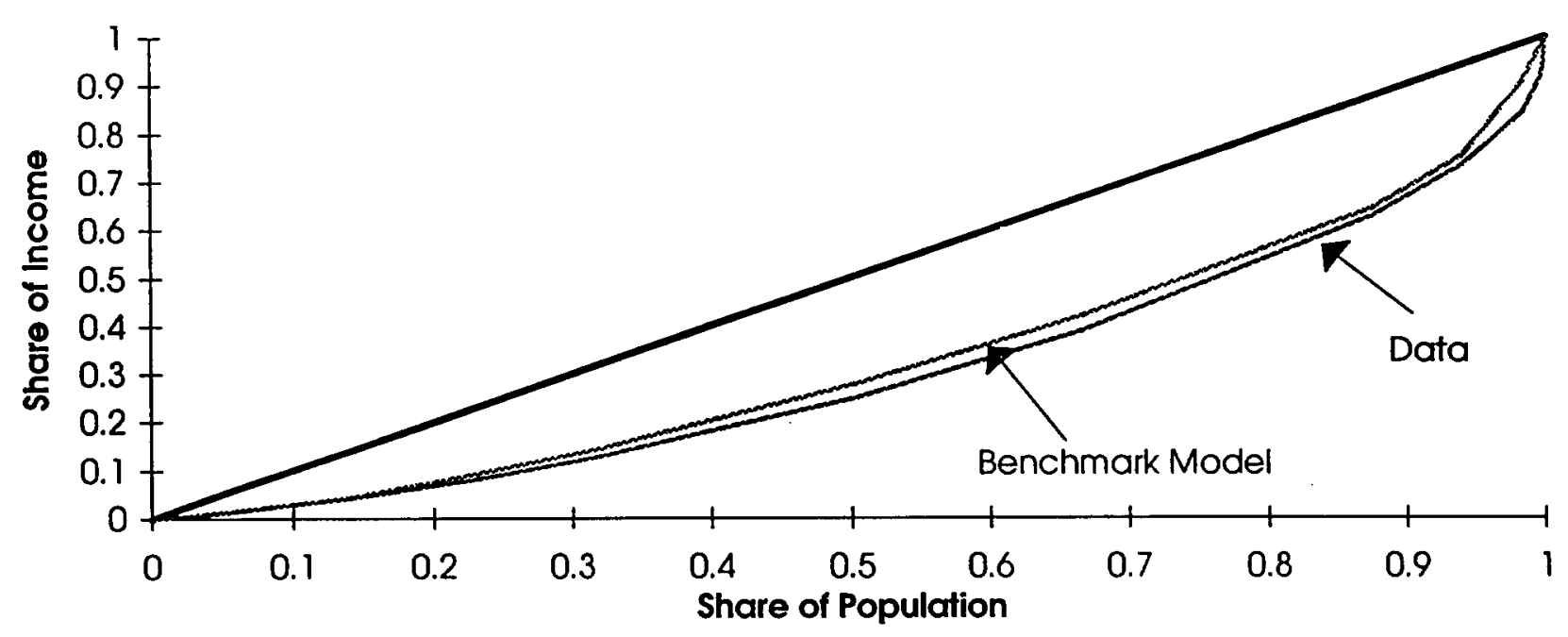

Sources: Internal Revenue Service; and authors' calculations. 
Figure 3: Distribution of Gross Income, 1989 Benchmark

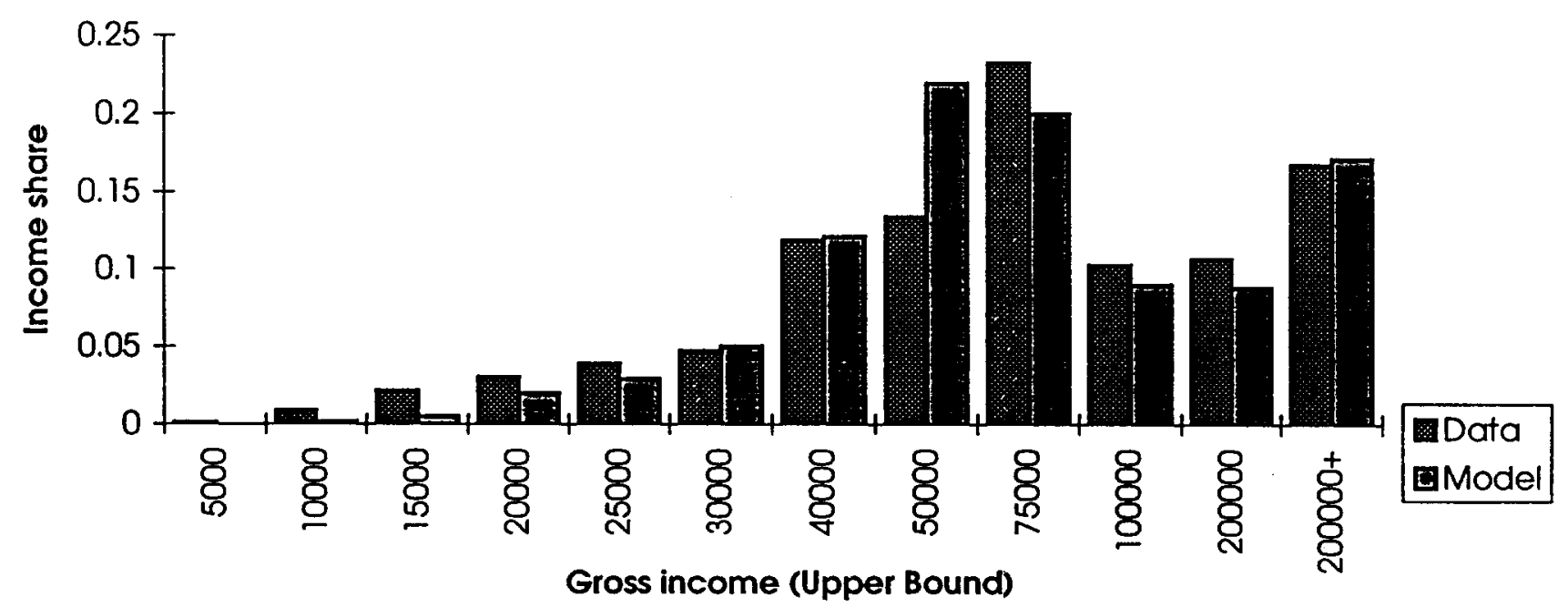

Sources: Internal Revenue Service: and authors' calculations. 
Figure 4: Distribution of Taxes Paid, 1989 Benchmark

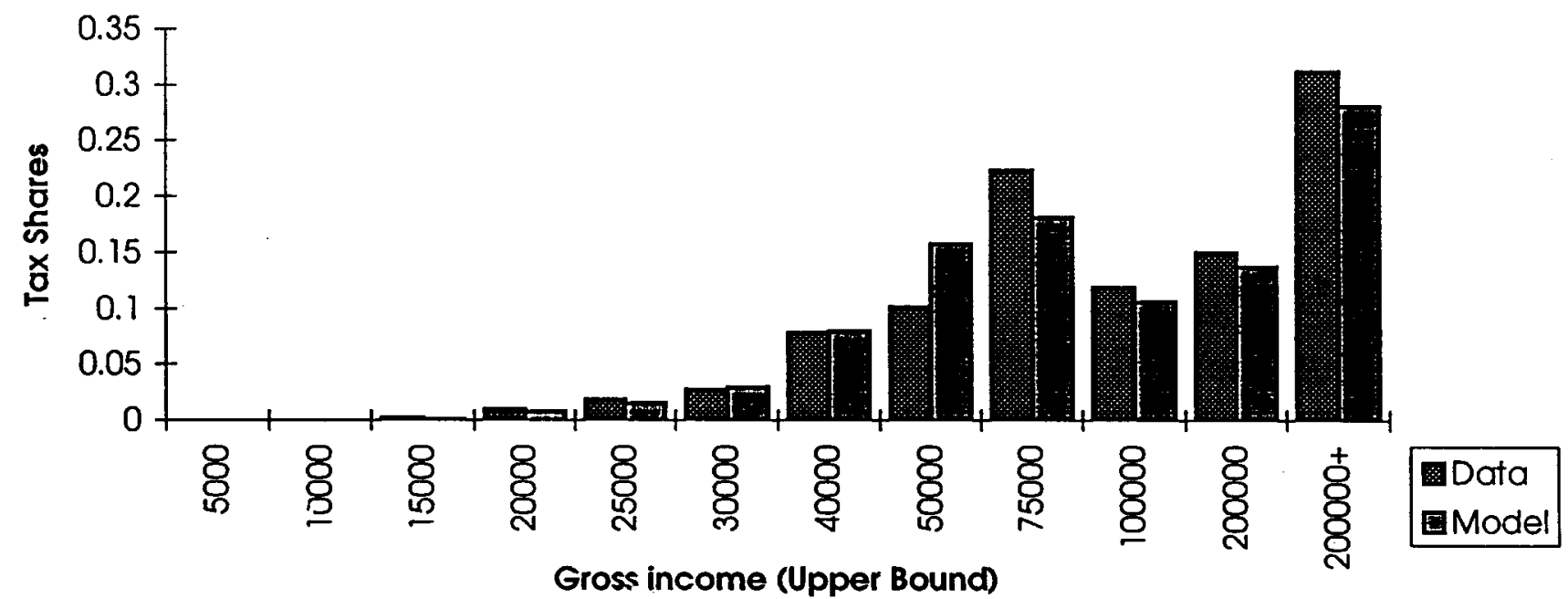

Sources: Internal Revenue Service; and authors' calculations. 


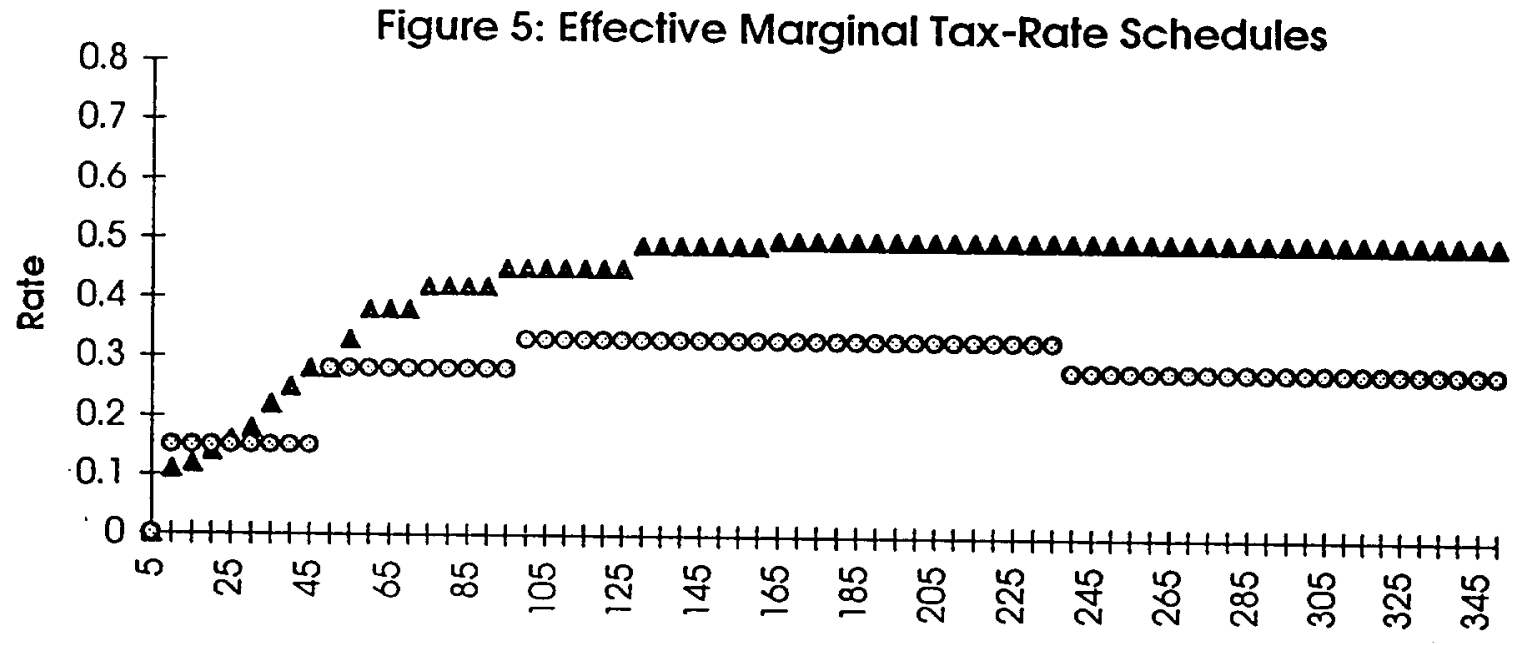

Gross Income (Thousands of 1989 dollars)

Sources: Internal Revenue Service; and authors' calculations. 


\section{Figure 6}

Tax Rate Comparisons: Cohort 3

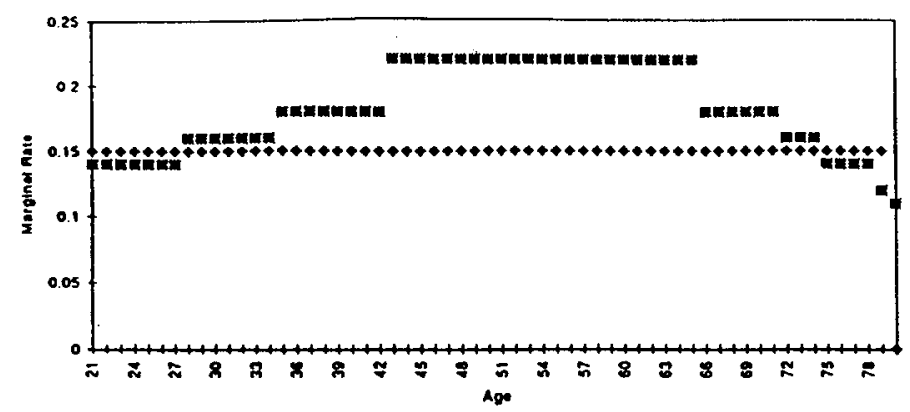

Labor Supply Comparisons: Cohort 3

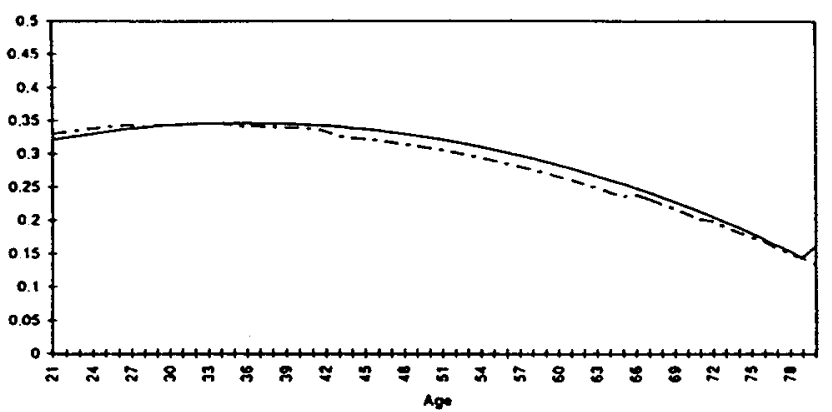

Wage Income Comparisons: Cohort 3

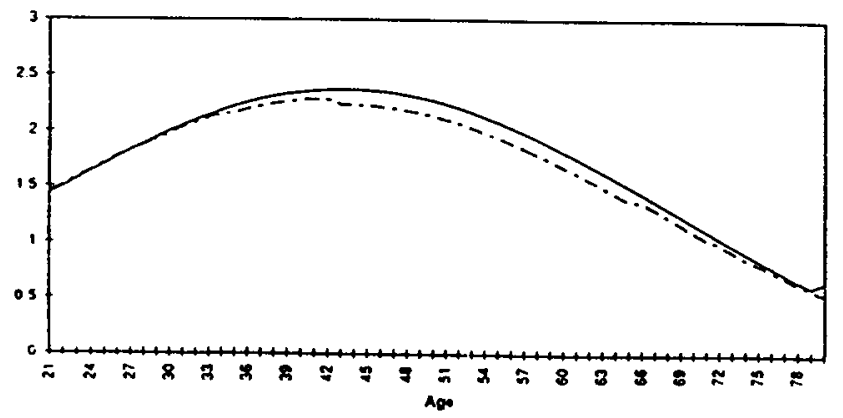

Asset Comparisons: Cohon 3

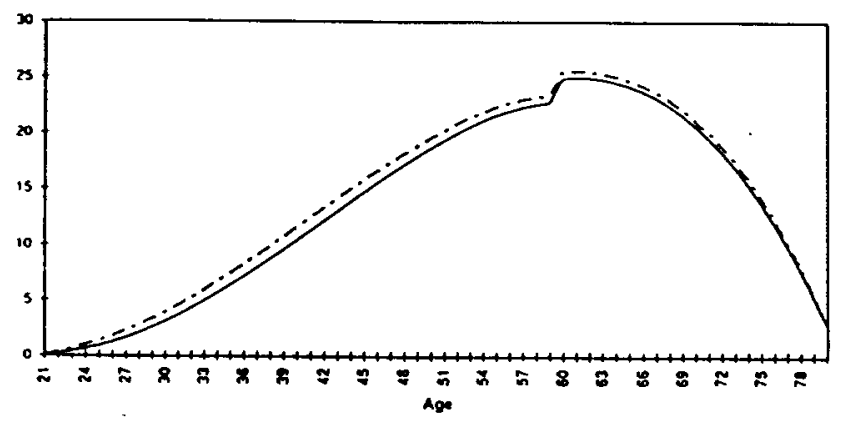

Asset income Comparisons: Cohort 3

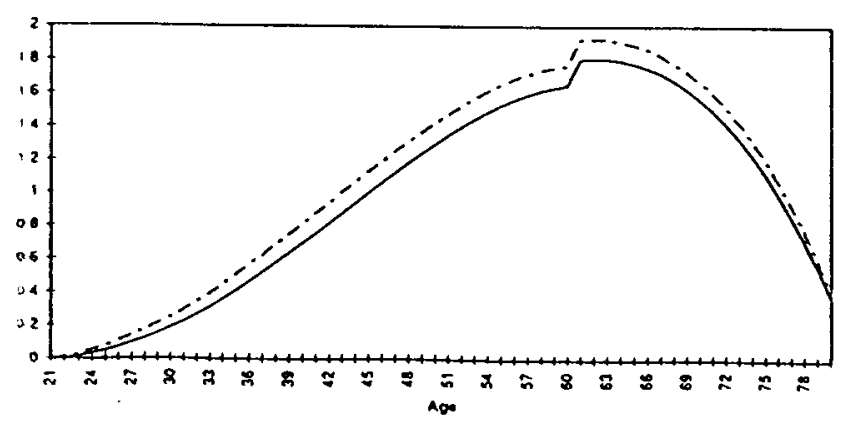

Tax Rate Comparisons: Cohort 11

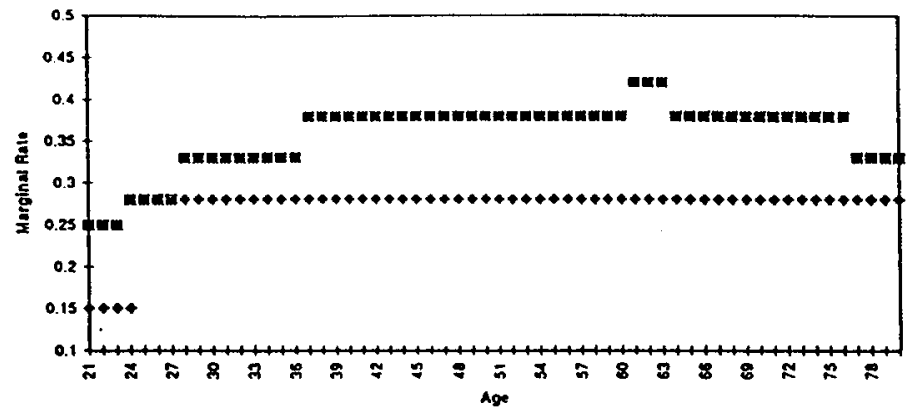

Labor Supply Comparisons: Cohort 11

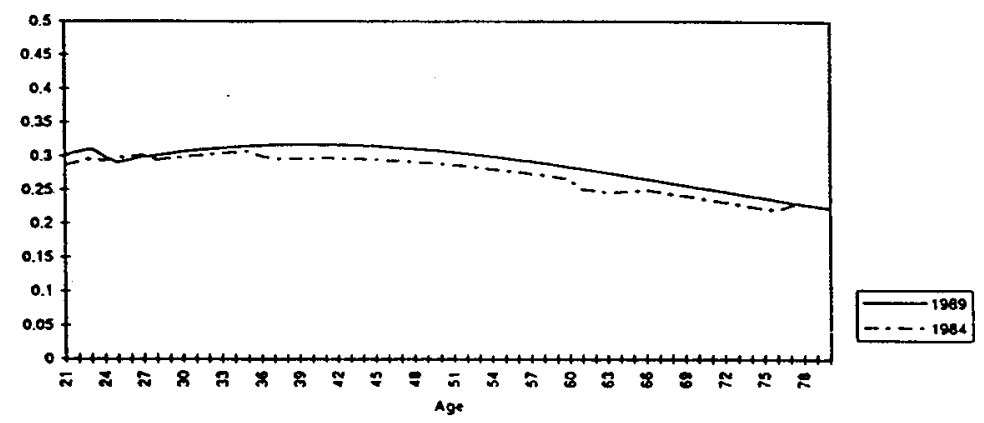

Wage Income Comparisons: Cohort 11

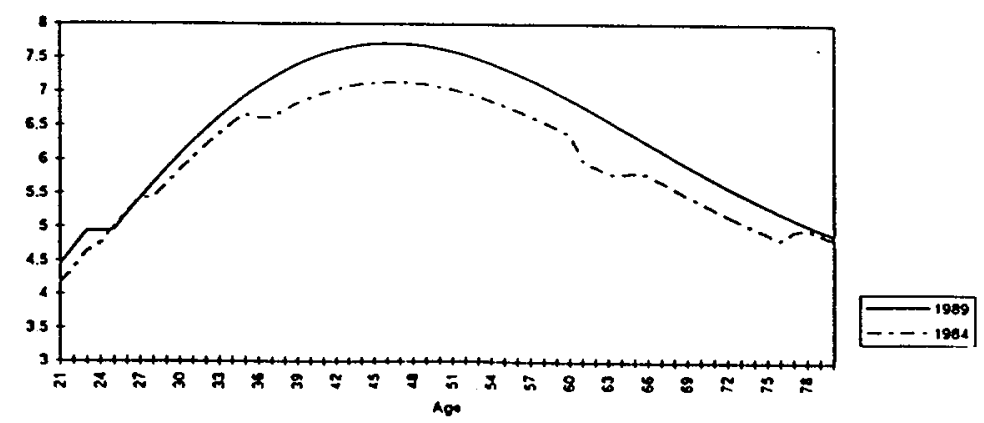

Asset Comparisons: Cohor 11

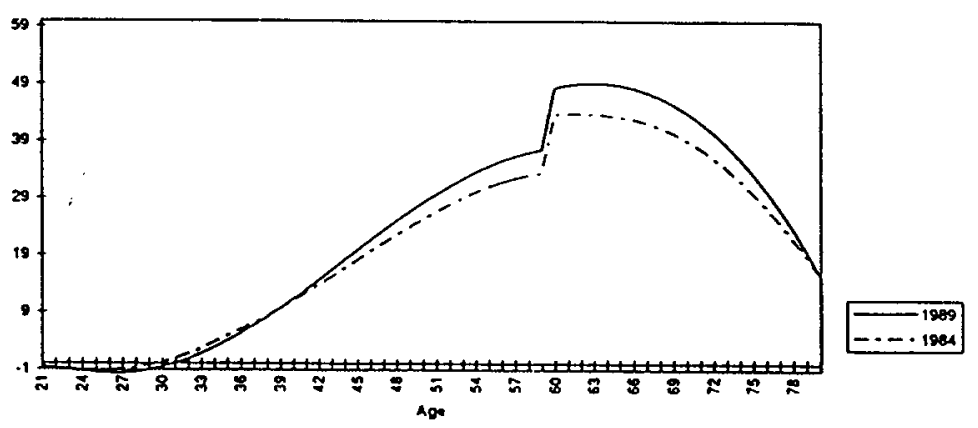

Asset Income Comparisons: Cohort 11

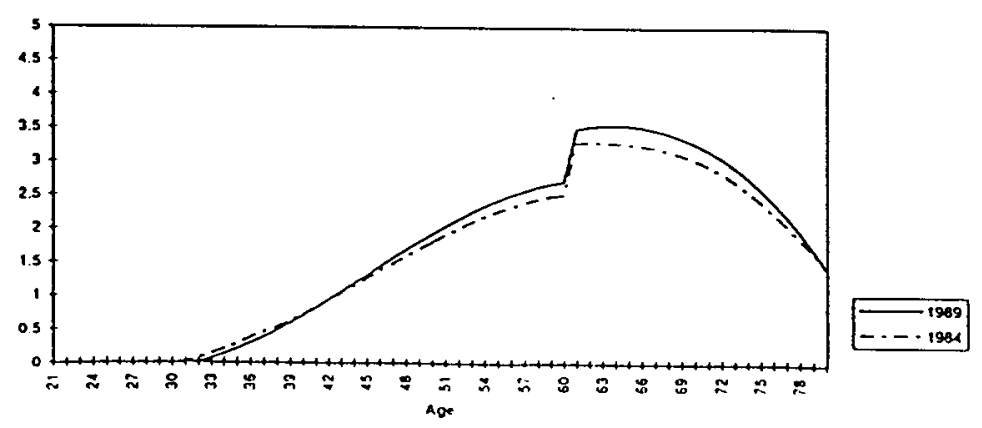


Figure 7

Labor Supply Comparisons: Cohort 3

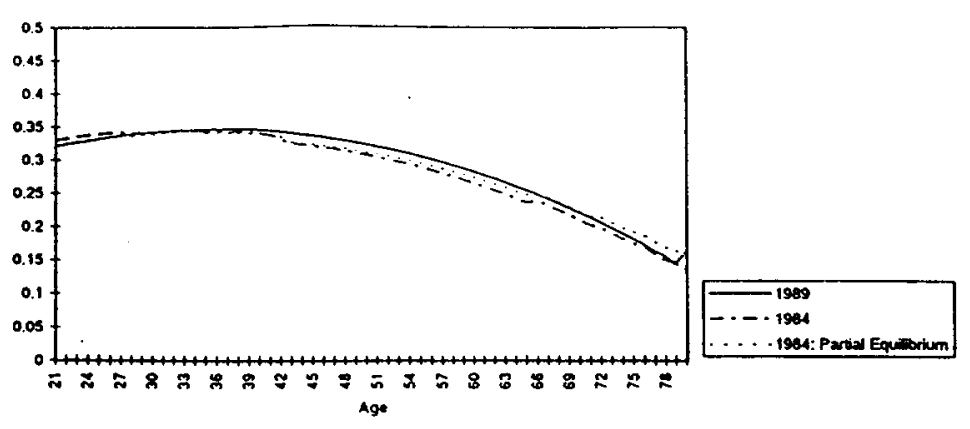

Wage income Comparisons: Cohon 3

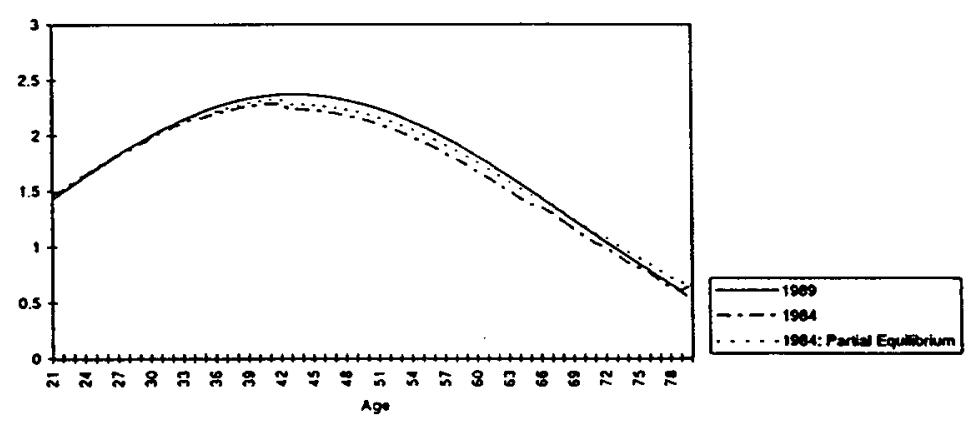

Asset Comparisons: Cohort 3

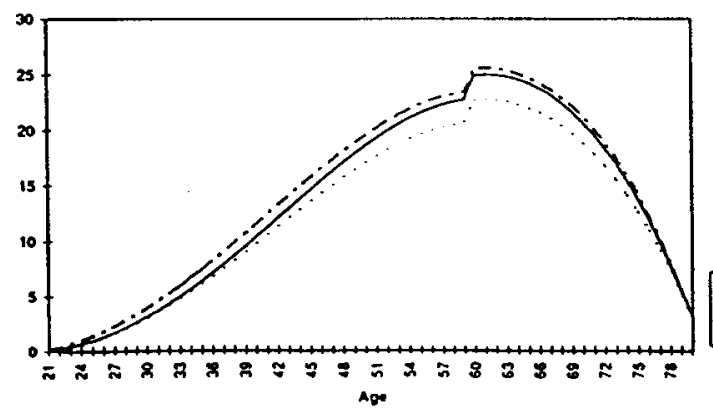

Asset Income Comparisons: Cohort 3

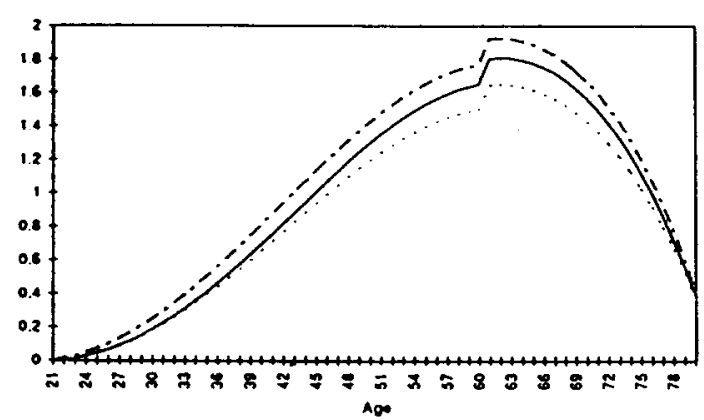

After-tax Real Interest Rales: Cohort 3

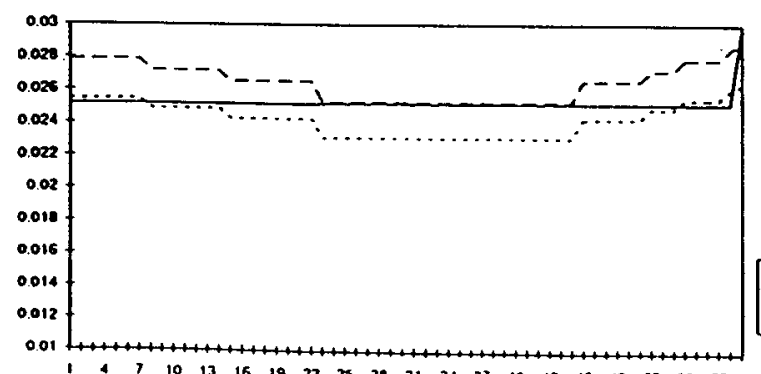
,
Labor Supply Comparisons: Cohon 11

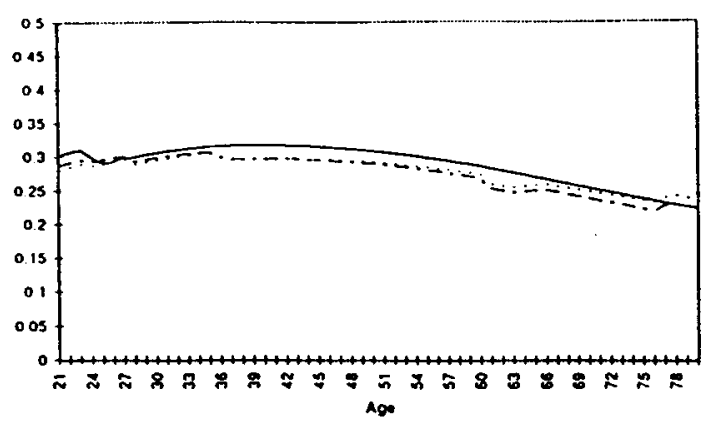

Wage Income Comparisons: Cohort 11

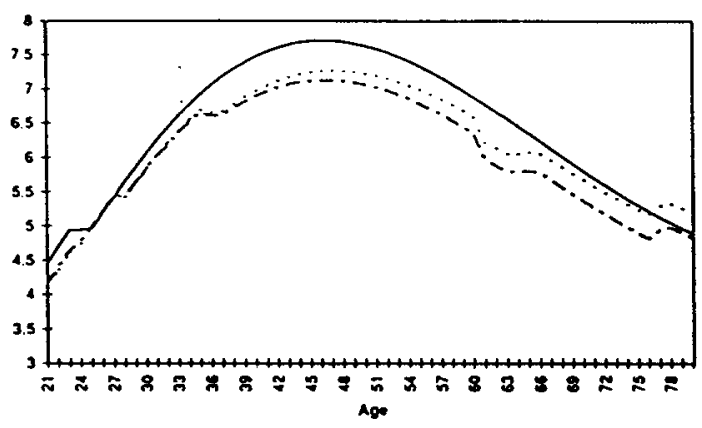

$-1009$ [... 1964: Parid Eculiorium

Asset Comparisons: Cohort 11

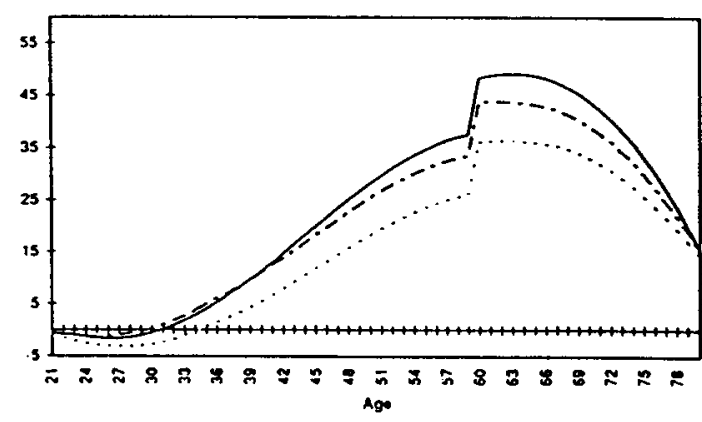

${ }_{-\cdot-1989}^{1909}$

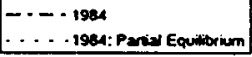

Asset Income Comparisons: Cohon 11

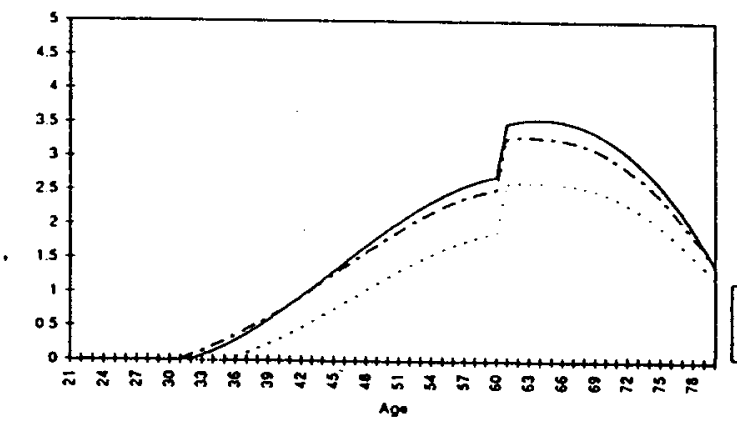

- 1909

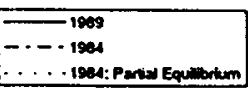

After-fax Real Interest Rates: Cohort 11

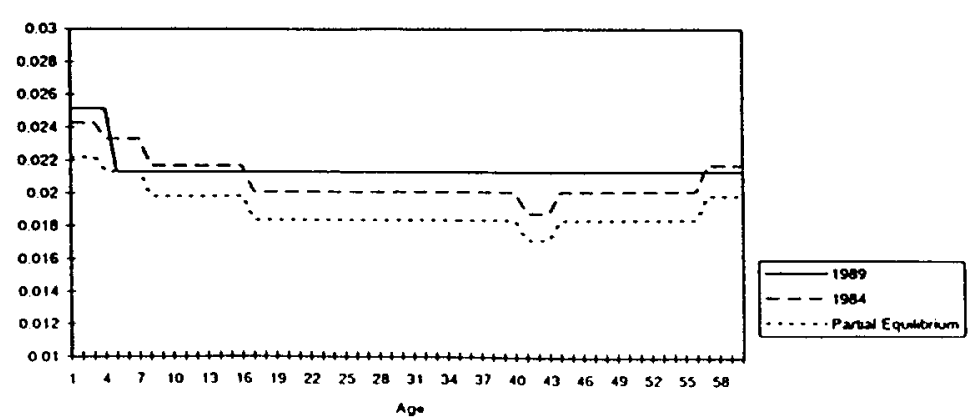


Figure 8: Welfare Gains from Shifting to 1989 Rate Structure

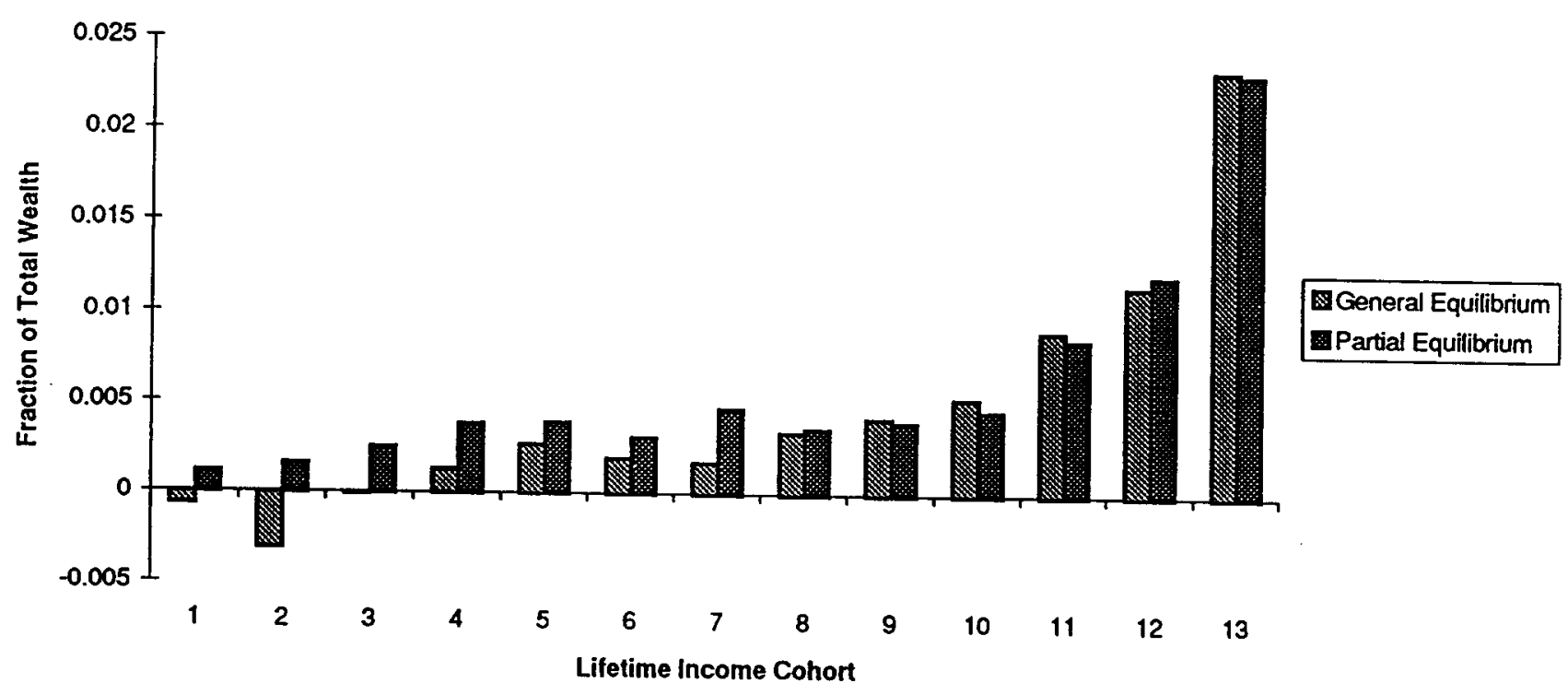

